\title{
Numerical Analysis of Serrated Chip Formation Mechanism with Johnson-Cook Parameters in Micro-Cutting of Ti6A14V
}

\author{
Zhongpeng Zheng ${ }^{1,2}$, Chenbing $\mathrm{Ni}^{2}$, Yun Yang ${ }^{2}$, Yuchao Bai ${ }^{2, *}$ (i) and Xin Jin ${ }^{1, *}$ \\ 1 School of Mechanical Engineering, Beijing Institute of Technology, Beijing 100081, China; \\ zhengzpbit@126.com \\ 2 Department of Mechanical Engineering, National University of Singapore, 9 Engineering Drive 1, \\ Singapore 117575, Singapore; nichenbing@126.com (C.N.); mpeyan@nus.edu.sg (Y.Y.) \\ * Correspondence: mpeby@nus.edu.sg (Y.B.); jinxinbit@163.com (X.J.)
}

Citation: Zheng, Z.; Ni, C.; Yang, Y.; Bai, Y.; Jin, X. Numerical Analysis of Serrated Chip Formation Mechanism with Johnson-Cook Parameters in Micro-Cutting of Ti6Al4V. Metals 2021, 11, 102. https://doi.org/ 10.3390/met11010102

Received: 5 December 2020 Accepted: 31 December 2020 Published: 6 January 2021

Publisher's Note: MDPI stays neutral with regard to jurisdictional clai$\mathrm{ms}$ in published maps and institutional affiliations.

Copyright: (C) 2021 by the authors. Licensee MDPI, Basel, Switzerland. This article is an open access article distributed under the terms and conditions of the Creative Commons Attribution (CC BY) license (https:// creativecommons.org/licenses/by/ $4.0 /)$.

\begin{abstract}
Previous studies have reported significant differences in the Johnson-Cook (J-C) parameters of Ti6Al4V alloy. Thus, various serrated chip morphologies, cutting forces, and cutting temperatures are obtained when different constitutive parameters are used for numerical and simulation analyses, which decreases the reliability of the simulation model. Therefore, it is necessary to investigate and analyze simulation errors due to differences in the J-C parameters. In this study, the mechanism of the serrated chip formation of Ti6Al4V is thoroughly analyzed using the uniformly proportional J-C parameters. The serrated chip sensitivity, shear band spacing, serrated segmentation frequency, chip serration intensity, temperature field, strain energy, and cutting force is obtained. This study aims to improve the accuracy and reliability of the micro-cutting simulation models, as well as a reference for the selection of J-C constitutive parameters of simulation with Ti6Al4V manufactured with different heat treatments and additive manufacturing.
\end{abstract}

Keywords: micro-cutting; numerical analysis; serrated chip; cutting simulation

\section{Introduction}

The development of technology has led to the demand for micro-products in the automotive, aerospace, electronics, medical implants, biomedicine, and robotics industries, among others. Micro-cutting is the key technology to suffice an industry in terms of functionality and size miniaturization [1]. Cheng et al. [2] indicated that the cutting depth is generally less than $200 \mu \mathrm{m}$, the processing size of micro turning is less than $100 \mu \mathrm{m}$, and the slots of the micro-milling processing width are within $50 \mu \mathrm{m}$. Given the exceptional material properties of titanium alloys, Ti6Al4V has been analyzed and applied to micro-cutting in several studies [3,4]. Owing to the low thermal conductivity of Ti6Al4V and relatively slow heat dissipation, it is relatively easy to form adiabatic shear bands and serrated chips in traditional micro-cutting machining [5,6]. Periodically fluctuating cutting forces are generated during the formation of serrated chips, which accelerates tool wear and affects the surface quality of machined parts $[7,8]$. However, the experimental studies regarding Ti6 Al4V processing technology continue to encounter several challenges, including cost and time constraints [9]. Therefore, the finite element numerical analysis method constitutes an imperative method to overcome experimental limitations and better explain the experimental mechanism [10,11].

An accurate cutting simulation model directly determines the accuracy of the formation mechanism of the serrated chips. In any finite element model (F.E.M.), an essential input defines the material properties; it is usually modeled by constitutive equations expressing the stress-strain response along with its dependence on strain rate, temperature, and work hardening [12]. Therefore, an accurate material constitutive corresponds to the key issue for developing an accurate cutting simulation model [13-15]. Currently, in the metal cutting simulation process, the Johnson-Cook (J-C) constitutive model is the most 
frequently used model in the finite element modeling of metal cutting [16,17], and the $\mathrm{J}-\mathrm{C}$ constitutive equation is commonly expressed as Equation (1). The J-C constitutive model considers the strain hardening effect, strain rate strengthening effect, and thermal softening effect. Simultaneously, the model reflects mechanical changes in metals under high strains, high strain rates, and high temperatures, which are suitable for different materials. The model can separate plastic, viscous, and thermal aspects [18]. Several previous studies utilized the J-C constitutive model to predict and explain the experimental mechanism, including the mechanochemical effect [19], stress distribution [20], distribution of displacement [21], cutting force, and serrated chip morphology [22].

$$
\sigma=\left(A+B \varepsilon_{p}^{n}\right)\left(1+C \ln \frac{\dot{\varepsilon}}{\dot{\varepsilon}_{p}}\right)\left[1-\left(\frac{T-T_{r}}{T_{m}-T_{r}}\right)^{m}\right]
$$

where $\sigma, \varepsilon, \dot{\varepsilon}$, and $\dot{\varepsilon}_{p}$ denote the equivalent flow stress, plastic strain, strain rate, and reference strain rate, respectively. Additionally, $T, T_{m}$, and $T_{r}$ denote the current temperature, melting temperature of the working material, and room temperature, respectively.

The J-C constitutive model is generally obtained by a split Hopkinson pressure bar (SHPB) test, and the experimental configuration allows a strain rate of $0.5-10^{4}[23,24]$, or the J-C constitutive constant is fitted via numerical methods [25]. Zhao et al. [26] obtained the effects of a high strain rate and elevated temperatures on the deformation behavior of laser assisted manufacturing FeCr alloy using the SHPB tests (Split Hopkinson Pressure Bar). Based on the experimental results, the J-C model and modified JohnsonCook model were established. Zhou et al. [27] investigated the mechanical properties of the titanium alloy Ti6Al4V through the SHPB test and the quasi-static tensile test to determine the parameters for the classical J-C constitutive model. Özel [25] presented a methodology to determine the deformation behavior of working materials under highstrain-rate metal cutting conditions by utilizing evolutionary computational methods to identify constitutive model parameters. The J-C constitutive model is mostly obtained through SHPB experiments; the J-C constitutive parameters for materials of the same composition are similar.

Although several studies regarding the constitutive of J-C materials on titanium alloys through SHPB or other methods have been conducted, the specific constitutive parameter values shown in Table 1 are different. Further analysis indicates that some parameters are significantly different. The maximum initial yield stress $A$ (1098 MPa [10]) increased by $50 \%$ compared to the minimum initial yield stress $A$ (742 MPa [28]). The highest strain hardening parameter $B$ (1092 $\mathrm{MPa}$ [29]) was $229 \%$ larger than the lowest strain hardening parameter $B$ (331.2 $\mathrm{MPa}[30])$. Similarly, the strain rate sensitivity coefficient $C$, thermal softening coefficient $m$, and hardening coefficient $n$ differ significantly in various studies. The difference in the J-C constitutive coefficients for the same Ti6Al4V material in various studies is mainly due to the differences in the experimental conditions and methods [31,32]. 
Table 1. Johnson-Cook constitutive parameters for Ti6Al4V and experimental conditions.

\begin{tabular}{cccccccc}
\hline Source & A/MPa & B/MPa & $n$ & $C$ & $m$ & $\dot{\varepsilon}_{0}$ & Method \\
\hline Johnson [30] & 862.5 & 331.2 & 0.34 & 0.012 & 0.8 & 1 & Split hopkinson pressure bar (SHPB) \\
Bois et al. [32] & 881 & 468 & 0.122 & 0.039 & 0.7 & $/$ & SHPB \\
Lee et al. [28] & 724.7 & 683.1 & 0.47 & 0.035 & 1.0 & $10^{-5}$ & SHPB \\
Lee et al. [33] & 782.7 & 498.4 & 0.28 & 0.028 & 1.0 & $10^{-5}$ & SHPB \\
Leseur et al. [29] & 1098 & 1092 & 0.93 & 0.014 & 1.1 & $/$ & SHPB \\
Seo et al. [34] & 997.9 & 653.1 & 0.45 & 0.0198 & 0.7 & 1 & SHPB \\
Khan et al. [35] & 1080 & 1007 & 0.5975 & 0.01304 & 0.7701 & 1 & SHPB \\
Li et al. [15] & 968 & 380 & 0.421 & 0.0197 & 0.577 & 0.1 & Numerical method \\
Özel et al. [25] & 803.85 & 544.57 & 0.36166 & 0.05 & 1.041 & $/$ & Numerical method \\
Özel et al. [25] & 883.99 & 598.87 & 0.36166 & 0.0335 & 1.041 & $/$ & Numerical method \\
Özel et al. [25] & 987.8 & 761.5 & 0.41433 & 0.01516 & 1.516 & $/$ & Inverse method \\
Braham [36] & 983 & 348 & 0.32 & 0.024 & 0.69 & 0.1 & SHPB \\
Meyer et al. [37] & 896.0 & 656.0 & 0.5 & 0.0128 & 0.8 & 1 & shear compression specimen (SCS) \\
Dorogoy et al. [38] & 880 & 695 & 0.36 & 0.04 & 0.8 & 1 & $/$ \\
Vyas et al. [39] & 856.41 & 840.26 & 0.880 & 0.11 & 0.663 & 1 & SHPB \\
Dumitrescu et al. [40] & 870 & 990 & 1.01 & 0.008 & 1.4 & 1 &
\end{tabular}

As shown in Table 1, the method to obtain the J-C constitutive constant is different, and the SHPB test corresponds to the mainstream method. For the same SHPB test method, the J-C constitutive constants that are obtained are different due to the various experimental conditions. Varying reference strain rate parameters, strain rate change gradients, and temperature change gradients were used in different studies. The actual stress-strain curves obtained from the tests are slightly different, as well as the J-C constitutive constants. Different J-C constitutive constants of Ti6Al4V were used for cutting simulation in several references [14,41]. Thepsonthi et al. [42] analyzed the two-dimensional elastoplastic viscoplastic finite element simulation of the formation of zigzag chips in the micro-milling of Ti6Al4V titanium alloy; the J-C constitutive constant of Ti6Al4V proposed by Lee et al. [33] was used. Sahoo et al. [43] proposed a hybrid approach for the prediction of cutting forces in the micro end milling of titanium alloy Ti6Al4V by finite element simulation; the J-C constitutive constant of Ti6Al4V proposed by Lee et al. [33] was used. Sun et al. [44] established the one-tool and double-tool cutting models based on the coupling Eulerian-Lagrangian (C.E.L.) finite element (F.E.) method; the J-C constitutive constant of Ti6Al4V proposed by Lee and Lin [29] was used. Bai et al. [45] proposed an analytical model of chip formation for an accurate prediction of the orthogonal cutting of Ti6Al4V; the J-C constitutive constant of Ti6Al4V proposed by Johnson [30] was used. Yadav et al. [46] established the finite element modeling of burr formation in the high-speed micro-milling of Ti6Al4V; the J-C constitutive constant of Ti6Al4V proposed was from Leseur et al. [28].

Moreover, Wan et al. [47] developed an analytical model to predict the position and shape of the dead metal zone in the micro-cutting process; the J-C constitutive constant of Ti6Al4V proposed was from Leseur et al. [28]. Kim [48] developed a predictive cutting force model for the cryogenic machining of Ti6Al4V; this model adopted the J-C constitutive constant proposed by Vyas et al. [39]. Du et al. [49] derived a new analytical formula for the friction coefficient at the tool-chip-workpiece interface. They applied it in the highspeed machining simulation of Ti6Al4V, the J-C constitutive model of Ti6Al4V proposed by Lee [33] was used in the cutting simulation modeling. Banerjee et al. [50] developed an F.E.A. model of the Effect of the minimum quantity lubrication (M.Q.L.) machining process to simulate cutting force and chip formation; the J-C constitutive constant of Ti6Al4V proposed was from Dumitrescu et al. [40]. Thus, different serrated chip morphology, cutting forces, and cutting temperatures are obtained when various constitutive parameters are used for numerical and simulation analyses. Additionally, note that the mechanical properties of additively manufactured (A.M.) Ti6Al4V are entirely different from traditional casting Ti6Al4V [51,52]. This also implies that the J-C constitutive of additively manufactured Ti6Al4V is significantly different from traditional casting. Therefore, the traditional 
$\mathrm{J}$-C constitutive parameters used to simulate the additive manufacturing Ti6Al4V process will also reduce the reliability of the results.

Therefore, it is necessary to analyze the simulation errors due to differences in the $\mathrm{J}-\mathrm{C}$ parameters. Yaich et al. [53] presented the influence of constitutive parameters on the simulation results of Ti6Al4V, including J-C constitutive parameters, damage parameters, and damage failure parameters. Wang et al. [54] conducted a shear localization sensitivity analysis for the Johnson-Cook constitutive parameters on serrated chips during the highspeed machining of Ti6Al4V. Gao performed simulations of high-speed machining Ti6Al4V using J-C constitutive methods proposed by Lee et al. [33], Merer et al., Khan et al. [35], and Seo et al. [34]. The results indicated that the parameters of the constitutive model proposed by Seo et al. are more accurate and the cutting force is closer to the real parameters [32]. Calamaz et al. [55] analyzed the influence of the material characteristics (strain softening, thermal softening, etc.) and machining parameters on the cutting forces and chip morphology. Özel et al. [56] performed Simulation of Machining Ti-6Al-4V Titanium Alloy using J-C constitutive methods proposed by Lee et al. [33], Johnson [30], and Leseur et al. [28]. Their research results found that Leseur's model is not found suitable for FE simulations. These do not consider the influence of the J-C constitutive parameters in the micro-cutting process. As the amount of material removal in the micro-cutting process is significantly lesser than that of traditional machining, which leads to the redistribution of thermal softening and hardening effects in the micro-cutting process, the influence of the $\mathrm{J}-\mathrm{C}$ constitutive parameters on serrated chips is not entirely similar to traditional cutting.

Therefore, the serrated chip formation mechanism using the Johnson-Cook parameters in the micro-cutting of Ti6Al4V is analyzed. Although several studies regarding the experiment and simulation of the serrated formation mechanism of Ti6Al4V have been conducted, a thorough analysis of the J-C constitutive parameters concerning the serrated chip formation mechanism in the micro-cutting of Ti6Al4V is limited. Aiming to reduce the inconsistency between the experimental and cutting simulation results due to varying $\mathrm{J}$-C constitutive parameters, as well as to increase the reliability of the cutting simulation model, the serrated chip formation mechanism with the Johnson-Cook parameters in the micro-cutting of Ti6Al4V are analyzed. Serrated chip sensitivity, shear band spacing, serrated segmentation frequency, chip serrated intensity, temperature field, and cutting force are obtained and analyzed. Further, this study provides guidance to improve the accuracy of cutting simulation models.

\section{Finite Element Model of Micro-Cutting}

\subsection{Geometric Model of Micro-Cutting}

The commercial software, Abaqus/Explicit, was used to establish an orthogonal micro-cutting model to accurately analyze the effect of J-C constitutive parameters on the formation mechanism of Ti6Al4V serrated chips. The model adopts temperaturedisplacement coupling in an eight-node element. Temperature-displacement coupling, a four-node element, was used by the tool model. In general, the cutting tool is rigid due to the significant hardness between the tool and working materials [57]. To balance the accuracy and efficiency of the model, the Lagrangian meshing technique used in micro-cutting models and local mesh refinement is required to reproduce the serrated chip better and decrease calculation time. The workpiece in the micro-cutting model is divided into two parts: the upper part that mainly corresponds to the chip layer and a grid with dimensions of $1 \mu \mathrm{m} \times 1 \mu \mathrm{m} \times 1 \mu \mathrm{m}$. The grid size decreases gradually and increases away from the cutting layer. All material properties of the workpiece are identical. The rake angle of the tool is $10^{\circ}$, the flank angle is $6^{\circ}$, and the radius of cutting wedge is $1 \mu \mathrm{m}$. The micro-cutting simulation geometry model of Ti6Al4V is shown in Figure 1. 
$\Delta$ Fixed boundaries

$\triangle$ No Y displacement

Mesh size: $1 \mu \mathrm{m} \times 1 \mu \mathrm{m} \times 1 \mu \mathrm{m}$

$t_{0}=20 \mu m \quad \gamma=6^{\circ} \quad \alpha=10^{\circ}$
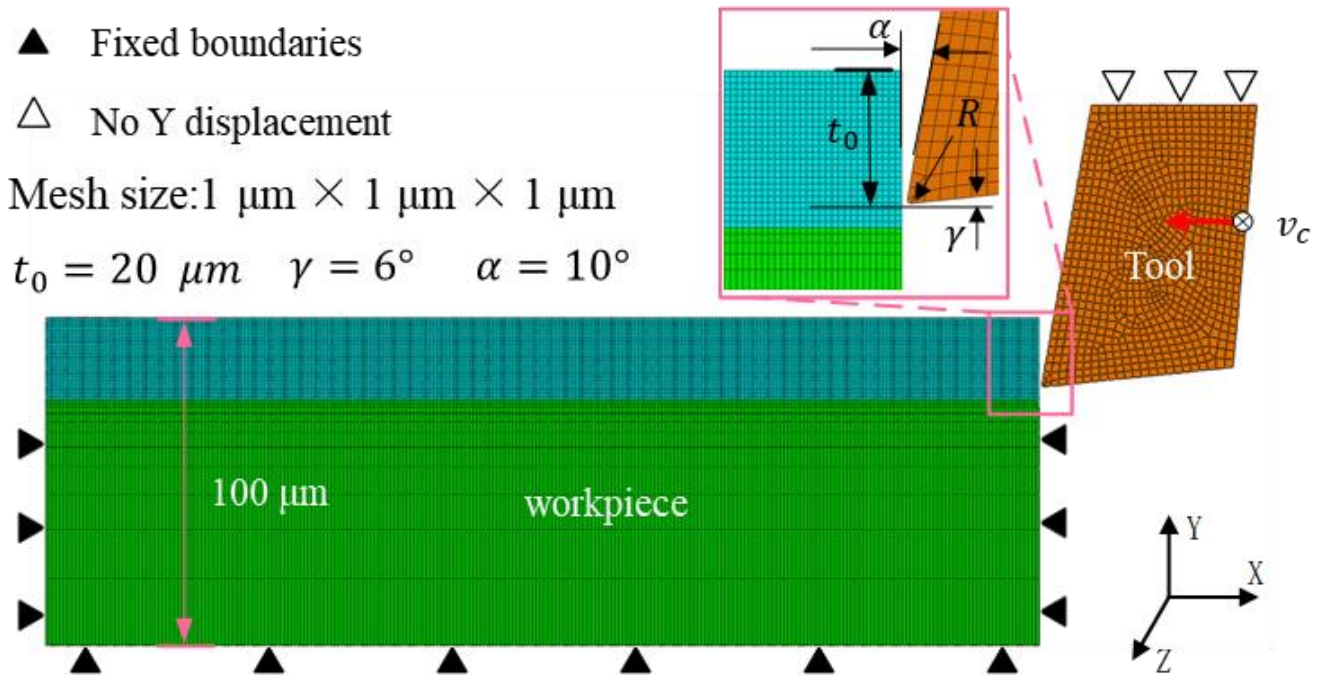

Figure 1. Geometric model and boundary conditions of the orthogonal micro-cutting simulation.

Boundary constraints correspond to the bottom and sides of the workpiece; the $Z$ and $Y$ directions of the tool are fixed. The degree of freedom in the $X$-direction of the tool is retained such that the tool can move in the X-direction. Simultaneously, the rake face of the tool is defined as the main contact surface, and the workpiece is defined as the slave contact surface. Therefore, the grid of the rake surface of the tool must exceed the grid size of the workpiece. The initial temperature of the entire model is set to $25^{\circ} \mathrm{C}$. Notably, compared with traditional machining parameters, the amount of material removal in the micro-cutting process is less, which leads to the redistribution of thermal softening and hardening effects in the micro-cutting process, the influence of the J-C constitutive parameters on serrated chips is not entirely similar to traditional cutting. Although the tool radius have a certain effect on the results, this article focuses on the analysis of the influence of the JC parameters on the constant tool radius. Therefore, the effect of size on the serrated chip was not considered in the simulation.

\subsection{Material Model}

Considering the micro-cutting simulation modeling of Ti6Al4V, selecting a reliable material for the constitutive model to evaluate the dynamic mechanical behavior of the material under different cutting conditions is crucial [58]. An accurate material flow stress model is necessary to represent the constitutive behavior of the working material under high strain rate deformation conditions. Therefore, formulating a material model that can truly reflect the stress-strain characteristics and the corresponding relationship between the strain rate strengthening and temperature of the material being processed constitutes the basis and key to ensure the accuracy of the micro-cutting simulation.

In the micro-cutting simulation model, the J-C constitutive parameters of Ti6Al4V are shown in Table 1, and their physical and mechanical properties are shown in Table 2. The physical and mechanical properties of the tool are listed in Table 3.

Table 2. Physical and mechanical properties of Ti6Al4V [22,59,60].

\begin{tabular}{|c|c|c|c|c|c|c|}
\hline $\begin{array}{l}\text { Density } \\
\left(\mathrm{kg} / \mathrm{m}^{3}\right)\end{array}$ & $\begin{array}{c}\text { Elastic } \\
\text { Modulus } \\
\text { (GPa) }\end{array}$ & $\begin{array}{l}\text { Poisson's } \\
\text { Ratio }\end{array}$ & $\begin{array}{c}\text { Thermal } \\
\text { Conductivity } \\
\left(\mathrm{W} / \mathrm{m}^{\circ} \mathrm{C}\right)\end{array}$ & $\begin{array}{l}\text { Specific Heat } \\
\left(\mathrm{J} / \mathrm{kg}^{\circ} \mathrm{C}\right)\end{array}$ & $\begin{array}{c}\text { Thermal } \\
\text { Expansion } \\
\text { Coefficient } \\
\left(/{ }^{\circ} \mathrm{C}\right)\end{array}$ & $\begin{array}{c}\text { Melting } \\
\text { Temperature } \\
\left({ }^{\circ} \mathrm{C}\right)\end{array}$ \\
\hline 4430 & $\begin{array}{l}109\left(50^{\circ} \mathrm{C}\right) \\
91\left(250^{\circ} \mathrm{C}\right) \\
75\left(750^{\circ} \mathrm{C}\right)\end{array}$ & 0.34 & $\begin{array}{c}6.8\left(20^{\circ} \mathrm{C}\right) \\
7.4\left(100^{\circ} \mathrm{C}\right) \\
9.8\left(300^{\circ} \mathrm{C}\right) \\
11.8\left(500^{\circ} \mathrm{C}\right)\end{array}$ & $\begin{array}{c}611\left(20^{\circ} \mathrm{C}\right) \\
624\left(100{ }^{\circ} \mathrm{C}\right) \\
674\left(300^{\circ} \mathrm{C}\right) \\
703\left(500^{\circ} \mathrm{C}\right)\end{array}$ & $9.0 \times 10^{-6}$ & 1605 \\
\hline
\end{tabular}


Table 3. Physical parameters of the carbide cutting tools [61].

\begin{tabular}{ccccc}
\hline $\begin{array}{c}\text { Density } \\
\left(\mathbf{k g} / \mathbf{m}^{3}\right)\end{array}$ & $\begin{array}{c}\text { Elastic Modulus } \\
(\mathrm{GPa})\end{array}$ & Poisson's Ratio & $\begin{array}{c}\text { Thermal Conductivity } \\
(\mathbf{W} / \mathbf{m ~ K})\end{array}$ & $\begin{array}{c}\text { Specific Heat } \\
(\mathbf{J} / \mathbf{k g ~ K})\end{array}$ \\
\hline 119,000 & 534 & 0.22 & 50 & 400 \\
\hline
\end{tabular}

In the cutting simulation process of Ti6Al4V, the cutting process undergoes three stages [62]. The first stage is initially linear elastic $(a-b)$, the second stage is plastic yielding with strain hardening $(\mathrm{b}-\mathrm{c})$, and the third stage is the material damage evolution stage $(\mathrm{c}-\mathrm{d})$. Among the three stages, the J-C constitutive model, which represents the plastic deformation stage of the material, belongs to the second stage. As shown in Figure 2, the solid line $l_{a b c d}$ denotes the stress-strain relationship considering material damage and the dashed line $l_{a b c d^{\prime}}$ denotes the stress-strain relationship without considering material damage. The strength of the material begins to decrease at the initial critical point $c$ indicating material damage. When it reaches point $d$, it reaches the fracture quasi-side wherein the material stiffness is completely lost and the material is fractured [63]. The material begins to fail after the plastic strain of the material reaches the initial damage point $c$. In the Ti6Al4V cutting simulation process, the equivalent plastic strain based on the integral point of the element is used to define the damage parameter $J$.

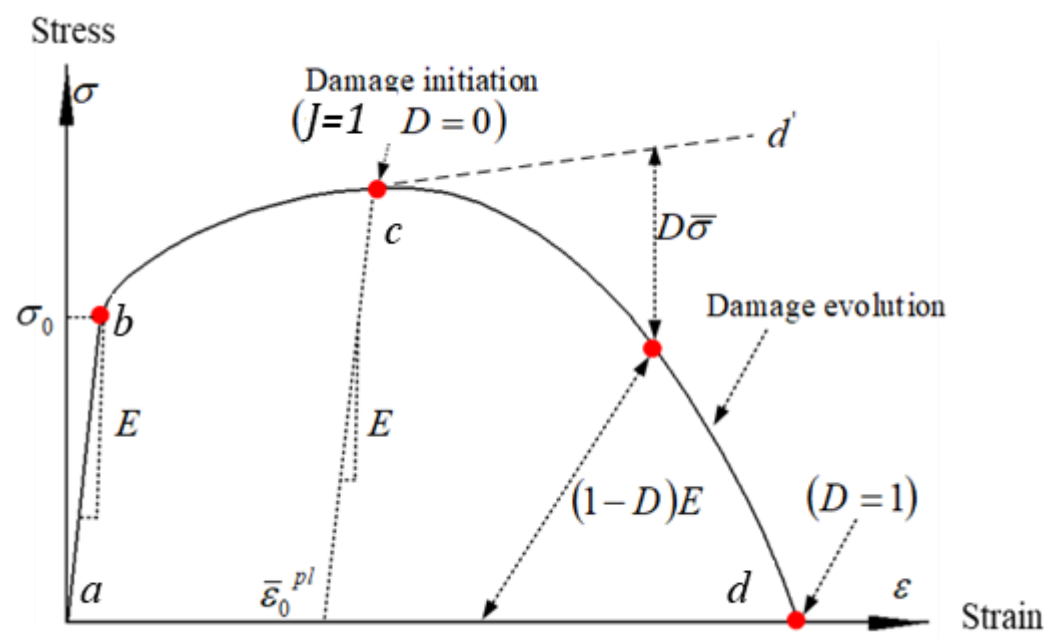

Figure 2. Stress-strain curve with progressive damage evolution.

When the damage parameter $J>1$, the workpiece material is fractured, the local material stiffness is completely lost, the element mesh is deleted, and chips begin to form. The J-C shear failure criterion and shear strain criterion are commonly expressed as Equation (2) [64]:

$$
J=\sum \frac{\Delta \bar{\varepsilon}}{\bar{\varepsilon}_{J C}}
$$

where $J$ denotes the damage initiation parameter, $\Delta \bar{\varepsilon}$ denotes the equivalent plastic strain increment, and $\bar{\varepsilon}_{J C}$ denotes the critical equivalent plastic strain. The specific expression is as Equation (3):

$$
\bar{\varepsilon}_{J C}=\left[D_{1}+D_{2} \exp \left(D_{3} \frac{P}{\bar{\sigma}}\right)\right]\left[1+D_{4} \ln \left(\frac{\dot{\varepsilon}}{\dot{\varepsilon}_{0}}\right)\right]\left(1+D_{5}\left(\frac{T-T_{r}}{T_{m}-T_{r}}\right)\right)
$$

The ratio of $p / \sigma$ is defined as the stress triaxiality, $D_{1}, D_{2}, D_{3}$ denotes the damage parameter of the material, $\dot{\varepsilon}$ denotes the equivalent strain rate, and $\dot{\varepsilon}_{0}$ denotes the reference strain rate. Additionally, $T$ denotes the current temperature, $T_{m}$ denotes the melting temperature of the workpiece material, and $T_{r}$ denotes the room temperature. The J-C damage parameters are listed in Table 4. 
Table 4. Johnson-Cook damage parameters [65].

\begin{tabular}{ccccc}
\hline $\boldsymbol{D}_{1}$ & $\boldsymbol{D}_{2}$ & $\boldsymbol{D}_{3}$ & $\boldsymbol{D}_{4}$ & $\boldsymbol{D}_{5}$ \\
Initial Failure Strain & Exponent Factor & Triaxiality Factor & Strain Rate Factor & \begin{tabular}{c} 
Temperature Factor \\
\hline-0.09
\end{tabular} \\
\hline & 0.25 & -0.5 & 0.014 & 3.87 \\
\hline
\end{tabular}

The stress gradually decreases during the simulated damage evolution stage. The material fails when $D=1(D \in[0,1])$ is the stiffness attenuation factor). The specific stress value is expressed as Equation (4) [65]:

$$
\sigma=(1-D) \bar{\sigma}
$$

The evolution stage of cutting damage involves two main ways, namely damage displacement and fracture energy. The fracture equation for the damage displacement method is expressed as Equation (5):

$$
D=\frac{\bar{u}_{p}}{\bar{u}_{f}}=\frac{L \bar{\varepsilon}_{p}}{\bar{u}_{f}}
$$

where $\bar{u}_{p}$ denotes equivalent plastic displacement, $\bar{u}_{f}$ denotes the equivalent plastic displacement at failure, $L$ denotes the characteristic element length, and $\bar{\varepsilon}_{p}$ denotes the equivalent plastic strain. The equation is as Equation (6):

$$
\begin{gathered}
D=1-\exp \left(-\int_{0}^{u^{-p}} \frac{\bar{\sigma}}{G_{f}} d \bar{u}_{p}\right) \\
G_{f}=\frac{(1-v)^{2}}{E} K_{c}^{2}
\end{gathered}
$$

where $u^{-p}$ denotes equivalent plastic displacement, $G_{f}$ denotes the fracture strain energy, $K_{C}$ denotes fracture toughness, $v$ denotes poisson's ratio, and $E$ denotes elastic modulus.

\subsection{Heat Conduction Model of the Workpiece-Tool}

In the micro-cutting process of Ti6Al4V, a large amount of heat is generated during the cutting process, and this causes the tool temperature to increase, and the material to soften. Heat is caused by plastic deformation in the primary deformation zone. It is difficult to transfer heat in a short time, and this increases the temperature of the workpiece and tool and affects the tool life, processed surface, and processing efficiency. The partial differential equation of plane orthogonal cutting heat conduction in the primary deformation zone is expressed as Equation (8) [22]:

$$
\begin{gathered}
\lambda\left(\frac{\partial^{2} T}{\partial x^{2}}+\frac{\partial^{2} T}{\partial y^{2}}\right)- \\
-\rho C\left(\mu \frac{\partial T}{\partial x}+v \frac{\partial T}{\partial y}\right)+\dot{Q}=0 \\
\dot{Q}=\kappa \sigma_{i j} \dot{\varepsilon}_{i j}
\end{gathered}
$$

where $\lambda$ denotes the thermal conductivity coefficient, $\rho$ denotes the material density, $C$ denotes the specific heat of the material, $\dot{Q}$ denotes the heat generation rate per unit volume of mechanical energy converted to thermal energy, $x$, and $y$ are cartesian coordinates, $\mu$ and $v$ denote the velocity component of the moving heat source in the $x$ and $y$ direction, $\sigma_{i j}$ denotes the material stress, $\dot{\varepsilon}_{i j}$ denotes the material strain, and $\kappa$ denotes the work-heat conversion coefficient.

In the finite element simulation cutting process, $\kappa$ is typically assumed such that $90 \%$ of the plastic deformation can be converted into heat and transferred to the workpiece and tool [61]. 
The secondary deformation zone is formed since the rake face is affected by chip crushing and friction. The heat generated by the friction increase as the temperature of the chip contact surface and increases the cutting heat generated in the process. It directly affects the wear and service life of the tool. During the micro-cutting process, the friction between the rake face and chips causes severe tool wear. Zorcv [66] proposed a viscous-slip friction model without considering temperature effects in 1963. The model obeys the coulomb's law of friction. The equation is as Equation (10):

$$
\tau=\left\{\begin{array}{l}
\mu \sigma_{n} \mu \sigma_{n}<\tau_{\max } \\
\tau_{\max } \mu \sigma_{n} \geq \tau_{\max }
\end{array}\right.
$$

where $\mu$ denotes the coefficient of friction, $\sigma_{n}$ denotes the positive pressure at the tool-chip interface, and $\tau_{\max }$ denotes the ultimate shear stress of the material, and the coefficient of friction $\mu$ is 0.3 .

The heat in the secondary deformation zone is mainly due to the friction between the rake face and chips. The heat generated by the friction is expressed as Equation (11):

$$
Q=\tau_{f} v_{f}
$$

where $\tau_{f}$ denotes the shear stress between the chip and rake face, and $v_{f}$ denotes the relative speed between the chip and rake face.

\section{Numerical Results and Analysis}

In the process of micro-cutting Ti6Al4V, the most important feature is that serrated chips are formed easily, which directly affects the cutting process. As the formation of serrated chips increases, there is an increase in the frequency and amplitude of the cutting force; the tool is significantly sensitive to distance, wear, and bounces, and the roughness of the machining surface increases. Therefore, it is extremely important to examine the mechanism of serrated chip formation. This section focuses on the formation mechanism of the Ti6Al4V serrated chip, the effect of the J-C constitutive parameters on the morphology mechanism of the serrated chip, and the effect of the J-C damage parameters on the formation mechanism of the serrated chip. The simulation cutting parameters remain identical to analyze the effect of the J-C constitutive parameters on the serrated chips. The cutting speed, cutting depth $\left(t_{0}\right)$, and cutting width $(w)$ correspond to $3 \mathrm{~m} / \mathrm{s}, 20 \mu \mathrm{m}$, and $0.2 \mathrm{~mm}$, respectively.

\subsection{Formation of Serrated Chips}

To explain the formation of serrated chips during the micro-cutting process, the distribution of stress and temperature field are used to study the changes of each stage of the detailed serrated chips. Additionally, the stress $S_{12}$ and temperature of the serrated formation process were sampled along the shear zone area. Stress S12 refers to the shear stress acting in the $Y$ direction on the Y.Z. plane, which is one of the components of stress [67], allowing the determination of whether the stress in the serrated chip is uniformly distributed. Currently, several studies have emphasized the formation mechanism of serrated chips. Wang et al. [68] indicated that the elastic strain is one of the dominant factors leading to the formation of shear bands, and the onset of the highly localized material softening effects. Vyast et al. [69] proposed the theory of periodic fracture and suggested that the serrated chips are formed by shearing and squeezing. However, Recht and Komanduri [70] indicated that a serrated chip is caused by the softness of the material due to the significant heat generated in the shear zone, and thus proposed the adiabatic shear theory. The representative theories correspond to the adiabatic shear theory.

Figure 3 presents the strain of the $S_{12}$ rule during the formation of the serrated chips in the micro-cutting of Ti6Al4V. Figure 4 presents the temperature field during the formation of the serrated chips in the micro-cutting of Ti6Al4V. Figures $4 \mathrm{a}$ and $5 \mathrm{a}$ present the material deformation state of the newly serrated chip when the previous chip is formed, and the 
deformation of the workpiece due to compressive stress, respectively. Furthermore, $\mathrm{S}_{12}$ denotes tensile stress, and the temperature in the shear zone is approximately $100-200{ }^{\circ} \mathrm{C}$. When the tool continues moving forward, the workpiece in the contact area that is continuously squeezed by the tool begins to bulge, as shown in Figures $3 \mathrm{~b}$ and $4 \mathrm{~b}$. At this stage, the temperature of the shear zone increases to $500{ }^{\circ} \mathrm{C}$, and the workpiece begins to soften in the shear zone.
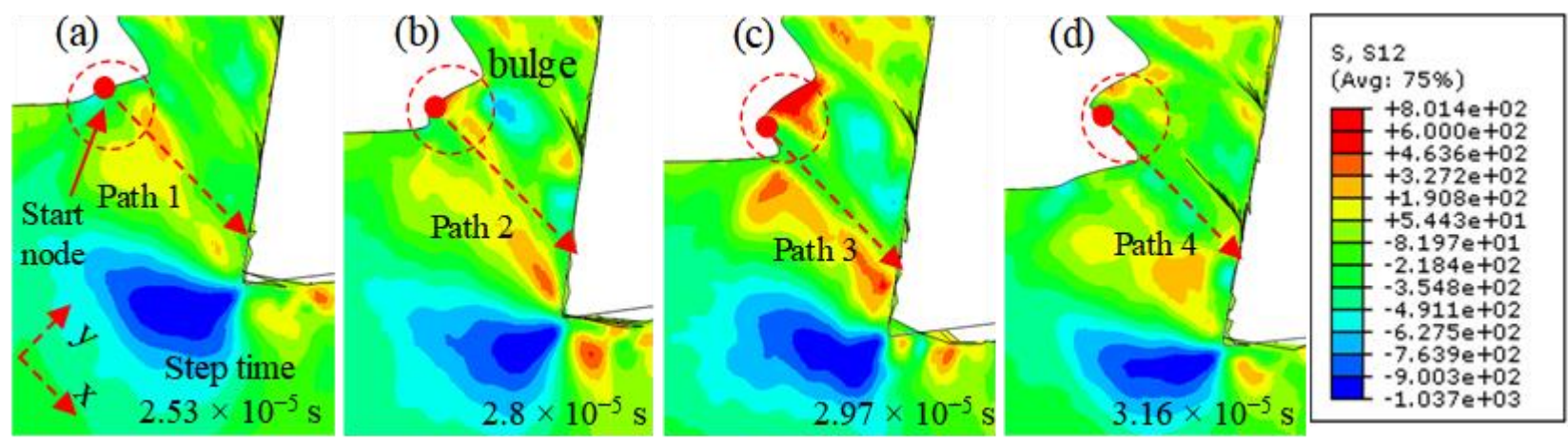

Figure 3. Distribution of stress $S_{12}$ during chip formation at different stages. (a) Serrated chip initiation; (b) strain localization; (c) thermal softening localization; (d) serrated chip formed.
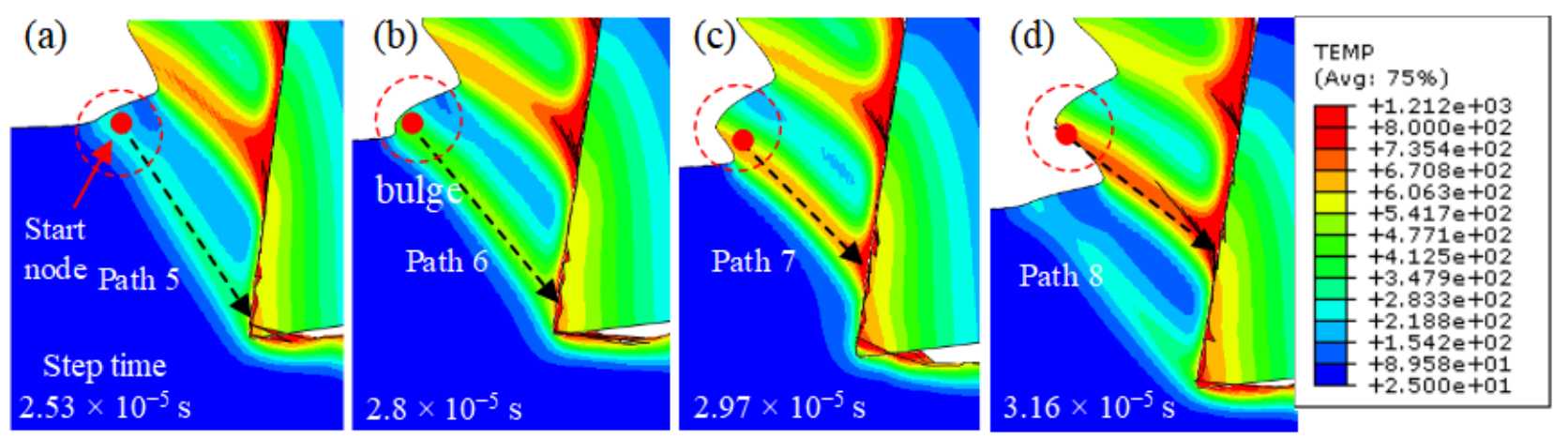

Figure 4. Temperature field distribution during chip formation at different stages. (a) Serrated chip initiation; (b) strain localization; (c) thermal softening localization; (d) serrated chip formed.
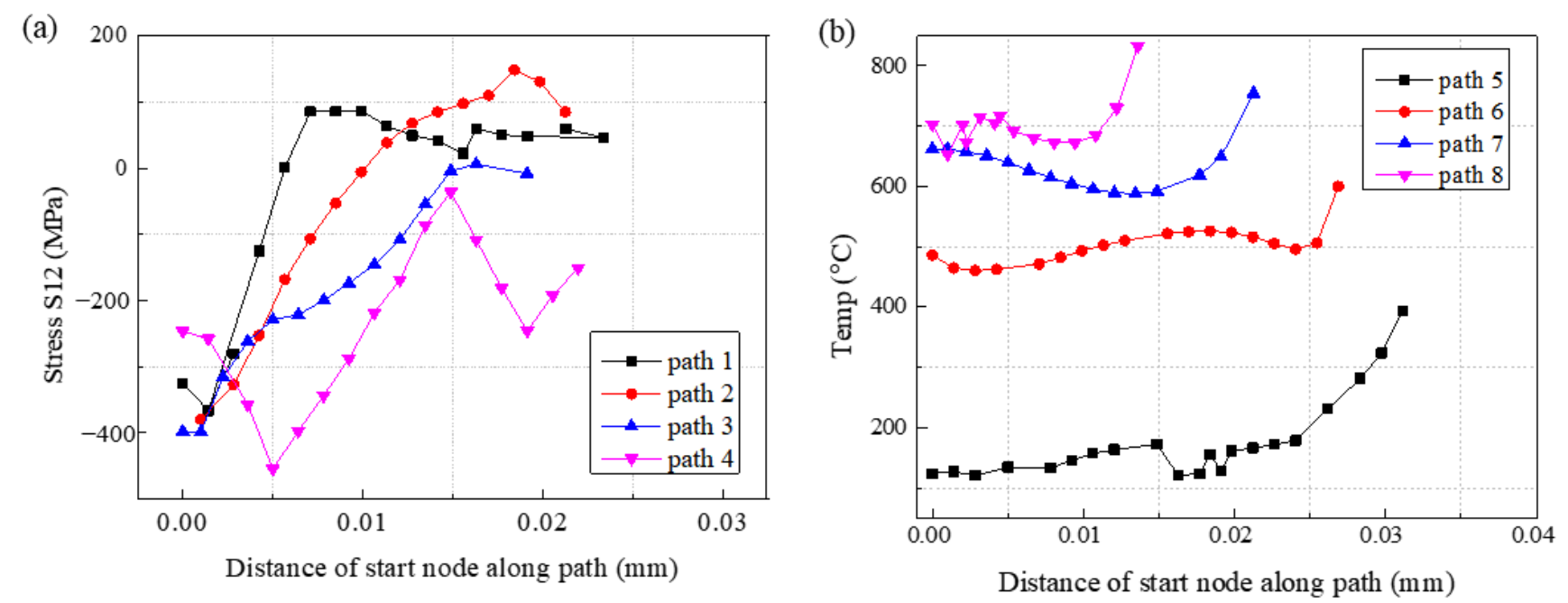

Figure 5. State variable distribution along the designated path. (a) Variation of stress $S_{12}$ during chip formation; (b) variation of temperature during chip formation. 
As shown in Figures $3 c$ and $4 c$, the stress concentration in the bulging area of the surface of the workpiece intensifies, thereby leading to the plastic instability of the workpiece; this phenomenon can be confirmed by Dargusch [71]. The free surface of the serrated chip is formed, and the adiabatic shear zone becomes more pronounced. This is mainly due to the plastic deformation in the primary deformation zone, which generates a significant amount of heat. Thus, the temperature goes up to $600{ }^{\circ} \mathrm{C}$ and results in thermal softening of the material in the adiabatic shear zone (A.S.B.), thereby rapidly decreasing the shear resistance. At the end of this phase, $S_{12}$ continues to increase and is confined to a relatively narrow area. When the micro-cutting process reaches the states in Figures $3 \mathrm{~d}$ and $4 \mathrm{~d}$, the expanded material continues to squeeze and narrows when the compressive stress $S_{12}$ decreases, where the adiabatic shear zone reaches the highest temperature, which exceeds $700{ }^{\circ} \mathrm{C}$. The serrated chip gradually starts to form from the back surface.

Figure 5 a presents the stress $S_{12}$ sampled along the path of the shear zone (path 1, path 2 , path 3 , and path 4 ). The compressive stress $S_{12}(+)$ apparently decreases with the formation of the serrated chips, thereby indicating that the micro-crack tendency occurs at the stage where the serrated morphology is formed. Figure $5 \mathrm{~b}$ presents the temperature along the path of the shear zone (path 1, path 2 , path 3 , and path 4). As clearly shown in the figure, the temperature in the shear zone increases with the formation of the serrated chips. The temperature is also observed to gradually increase as it moves along the path of the shear zone, which indicates that the temperature of the secondary deformation zone exceeds the temperature of the primary deformation zone. This viewpoint is provided in a previous study by Liu [72]; it also indicates that the cutting simulation model is reliable.

\subsection{Analysis of J-C Constitutive Parameters on Chip Morphology}

To reveal the dependence of J-C parameters on serrated chip morphology, J-C constitutive models with different gradients were designed. The J-C constitutive parameters proposed by Seo et al. [34] are as original parameters, and the original J-C constitutive parameters are listed in Table 1 . The gradients are obtained as $-10 \%,-20 \%,-30,+10 \%$, $+20 \%$, and $+30 \%$ of the original parameter values. The variation of Johnson-Cook constitutive parameters for Ti6Al4V is shown in Table 5 . The cutting speed, depth, and width correspond to $3 \mathrm{~m} / \mathrm{s}, 20 \mu \mathrm{m}$, and $0.2 \mathrm{~mm}$, respectively.

Table 5. The variation of Johnson-Cook constitutive parameters for Ti6Al4V.

\begin{tabular}{ccccccc}
\hline No. & Range & A & B & n & C & m \\
\hline 1 & $+30 \%$ & 1297.27 & 849.03 & 0.585 & 0.02574 & 0.91 \\
2 & $+20 \%$ & 1197.48 & 783.72 & 0.54 & 0.02376 & 0.84 \\
3 & $+10 \%$ & 1097.69 & 718.41 & 0.495 & 0.02178 & 0.77 \\
4 & Seo et al. [34] & 997.9 & 653.1 & 0.45 & 0.0198 & 0.7 \\
5 & $-10 \%$ & 898.11 & 587.79 & 0.405 & 0.01782 & 0.63 \\
6 & $-20 \%$ & 798.32 & 522.48 & 0.36 & 0.01584 & 0.56 \\
7 & $-30 \%$ & 698.53 & 457.17 & 0.315 & 0.01386 & 0.49 \\
\hline
\end{tabular}

Schulz [73] proposed a coefficient to express the degree of the serrated chip $G_{s}$. In the study, to compare the effect of different constitutive parameters on the serrated chip, the sensitivity coefficient $S_{i}$ is expressed as follows:

$$
\begin{gathered}
G_{s}=\frac{H-h}{h} \\
S_{i}=\frac{G_{s}-G_{\text {original }}}{G_{\text {original }}} \times 100 \%
\end{gathered}
$$

where $H$ denotes the height of the tooth top of the serrated chip and $h$ denotes the root height of the serrated chip. 
Figure 6 presents the distribution of equivalent plastic strain (PEEQ) of the serrated chip of Ti6Al4V under different J-C constitutive model parameters. The Ti6Al4V chip apparently exhibits significant differences when various J-C constitutive parameters are changed under the same cutting parameters. When the strain rate sensitivity coefficient $C$ increased from $-30 \%$ to $+30 \%$, the chip morphology changed from band chips to serrated chips, and the serrated sensitivity parameter $S_{i}$ gradually increased from a negative to a positive value. Thus, when the initial yield stress $A$ gradually increases, more energy is required when the same plastic deformation occurs. In the primary deformation area of the chip, the heat converted by plastic deformation increases, making the degree of jaggedness more apparent, further confirming the indications by Wang et al. [54]. However, the micro-cutting simulation of the study indicates that the hardening modulus $B$ is not similar to that described by Wang et al. As shown in Figure 6, the serrated sensitivity coefficient increases with increasing strain rate sensitivity coefficient $C$, which indicates the effect is the same as the initial yield stress $A$.

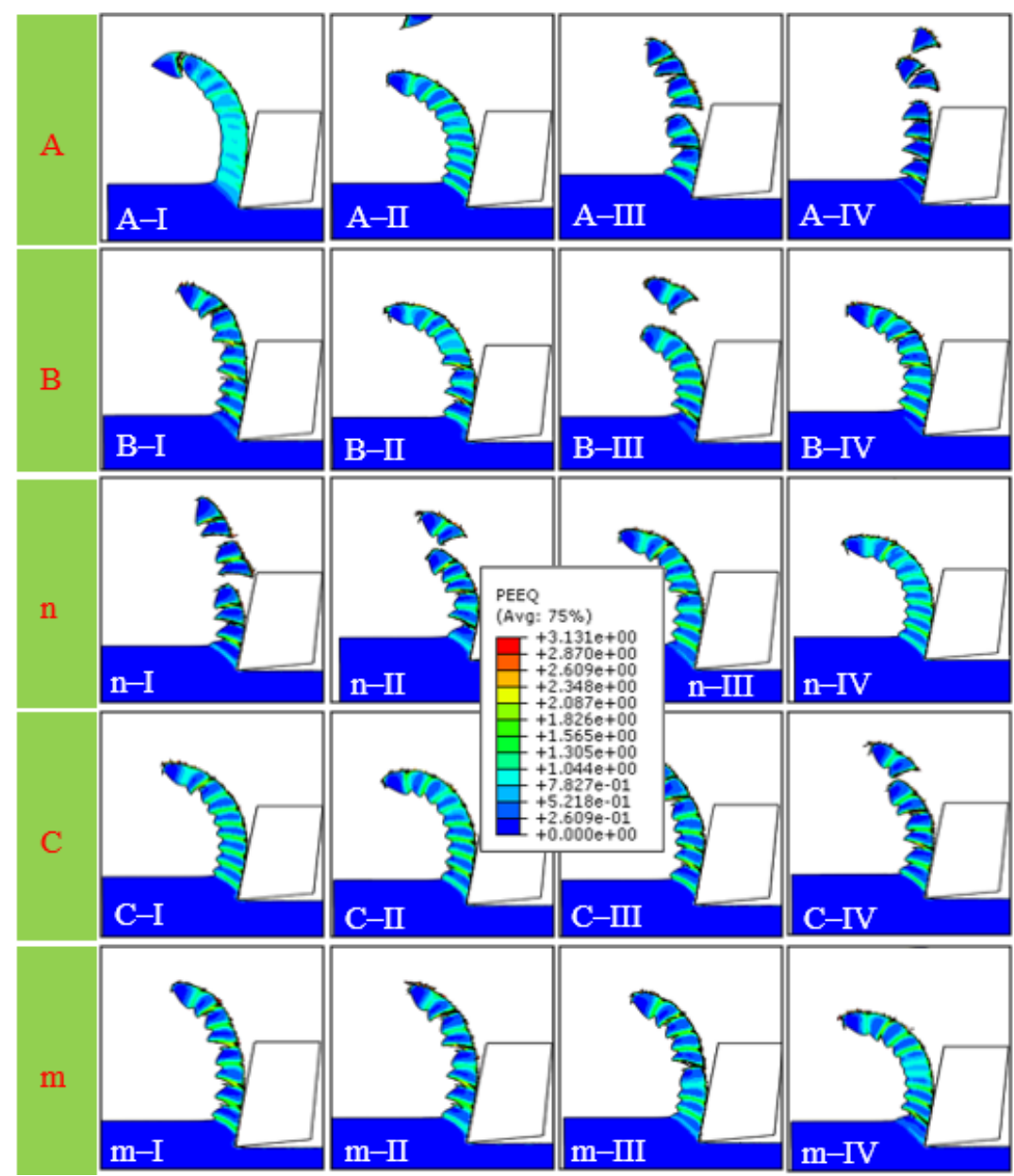

Figure 6. The result of serrated chip formation under different J-C parameters for cutting speed of $3 \mathrm{~m} / \mathrm{s}$. $A$ : initial yield stress, $B$ : hardening modulus, $n$ : strain rate dependency coefficient, $C$ : strain rate sensitivity coefficient, $m$ : thermal softening coefficient. I, II, III, and IV correspond to variation of the original J-C constitutive parameters $(-30 \%,-10 \%,+10 \%$, and $+30 \%$, respectively). 


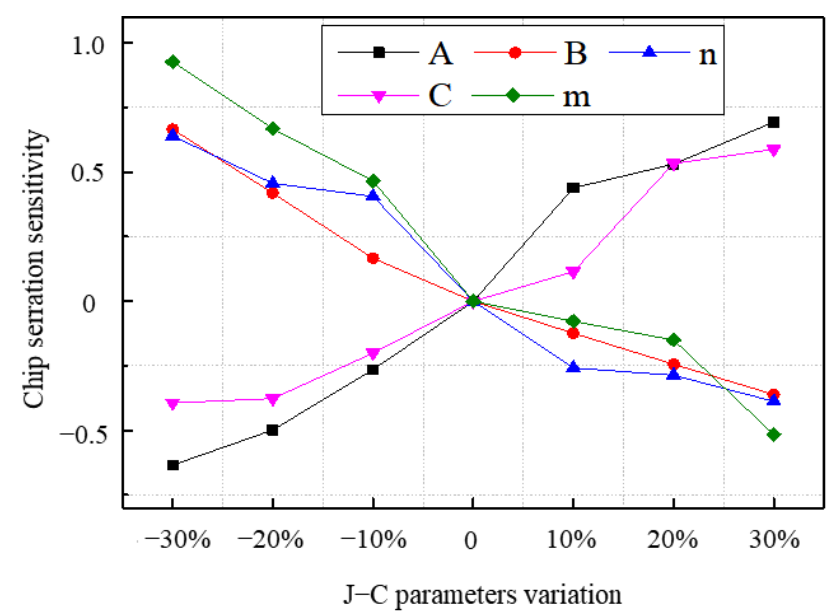

Figure 7. Sensitivity analysis of serrated chip under different variations of the original $\mathrm{J}$-C constitutive parameters $(A, B, n, C, m)$.

Conversely, the serrated sensitivity parameter $S_{i}$ exhibits decrease with increasing hardening modulus $B$, strain rate dependency coefficient $n$, and thermal softening coefficient $m$. When the J-C parameters $B, n$, and $m$ increase from -30 to $+30 \%$ of the original parameters, the serrated sensitive parameters $S_{i}$ a decrease from positive to negative values. This result is mainly due to the increase in the J-C parameters $(B, n, m)$, leading to increased hardening capacity of the material. Ultimately, the degree of serrated chips decreases.

As shown in Figure 7, the initial yield stress $A$ and the thermal softening coefficient $m$ have the greatest effect on the sensitivity coefficient of the serrated chip. When the initial yield stress $A$ decreases from -30 to $+30 \%$ based on the original value, the serrated sensitivity coefficient $S_{A}$ increases from -63 to $+69 \%$. The thermal softening coefficient $m$ is within the same range and the serrated chip sensitivity coefficient $S_{m}$ decreases from +60 to $-17 \%$.

Figure 8a presents a micro-cutting simulation model without considering temperature, and Figure $8 \mathrm{~b}$ presents a micro-cutting simulation model considering the temperature. The constitutive parameters and cutting parameters are identical. The micro-cutting simulation model considering temperature exhibits apparent adiabatic shear bands and serrated chips, while the cutting simulation model that does not consider temperature effects does not exhibit the serrated chips. This further illustrates that the plastic deformation in the shear zone generates a significant amount of heat and the adiabatic shear zone undergoes softening.

(a)

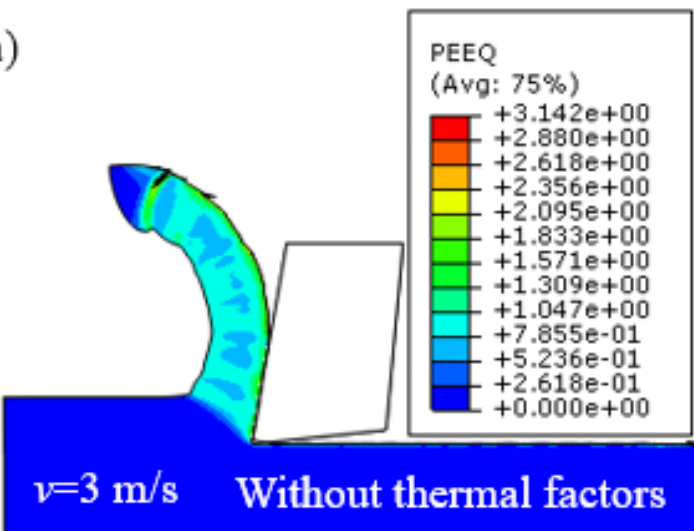

(b)
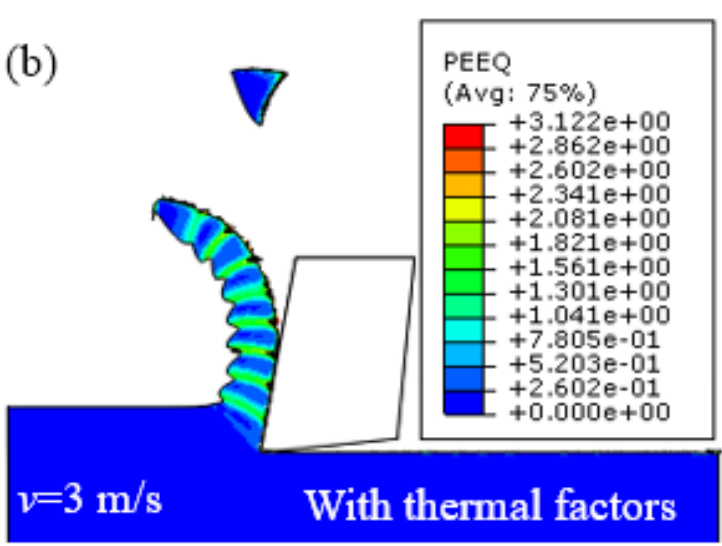

Figure 8. Comparison of simulation results with and without thermal factors. (a) chip morphology without thermal factors; (b) chip morphology with thermal factors. 
To further examine the frequency of the serrated chip and the chip serration intensity (C.S.I.) of the titanium alloy Ti6Al4V, an equivalent plastic strain was sampled along the middle of the chip. The specific path is shown in Figure 9a with the equivalent plastic strain curve. In this section, the C.S.I. proposed by Kouadri et al. [53] is used to represent the compression deformation of the serrated chip and is expressed as follows in Equation (14):

$$
\text { CSI }=\frac{\varepsilon_{\text {p.peak }-\varepsilon_{\text {p.valley }}}}{\varepsilon_{\text {p.valley }}}
$$

where $\varepsilon_{\text {p.peak }}$ denotes the equivalent plastic strain at the top of the tooth and $\varepsilon_{\text {p.valley }}$ denotes the equivalent plastic strain at the root of the tooth.

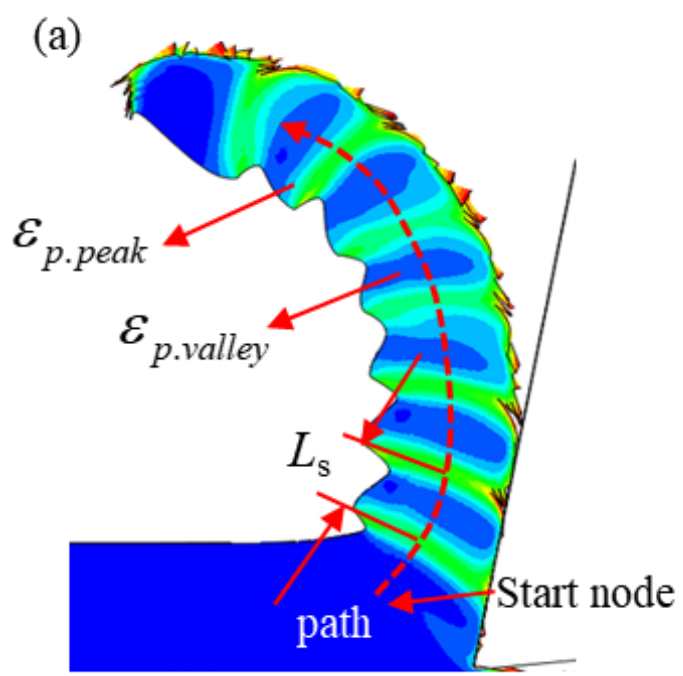

(b)

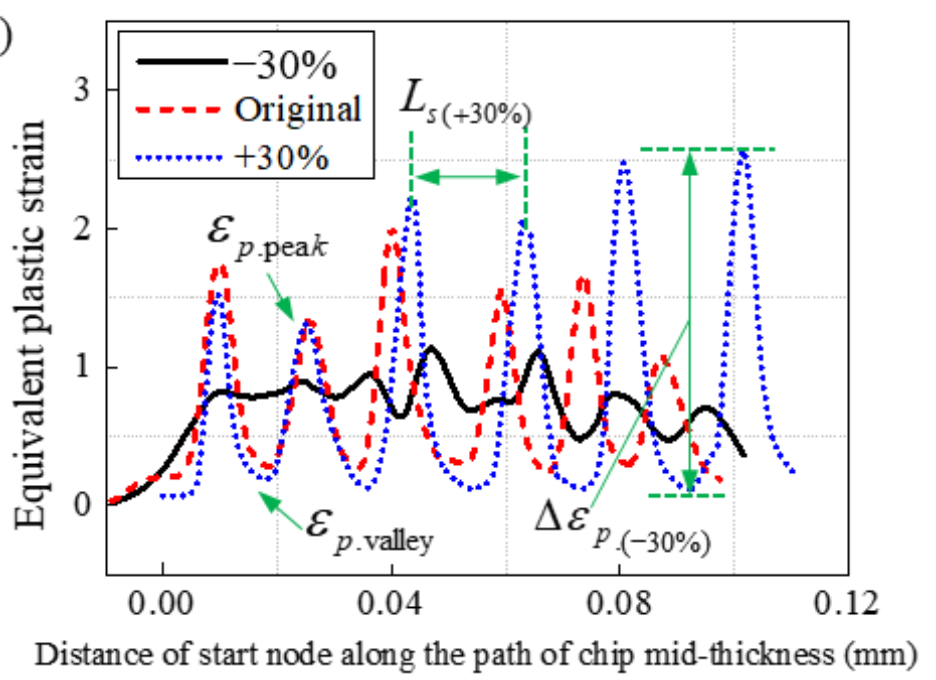

Figure 9. Dependency of the equivalent plastic strain evolution on initial yield stress $A$. (a) Design path along the middle thickness of the chip; (b) comparison of the equivalent plastic strain under different variation of the initial yield stress $A$ ( $-30 \%$, original, $+30 \%$, respectively).

The serrated frequency refers to the number of serrated chip units per unit time or length. Belhadi et al. calculated the serrated frequency by measuring the length and speed of a single serrated chip. The formation of the serrated chips is usually accompanied by the appearance of adiabatic shear bands. Therefore, the peaks of the adiabatic shear bands are used as the dividing line. The expression used to calculate the frequency of the serrated chips is presented by Equation (15) as follows:

$$
f_{\text {chip }}=1000 \frac{l_{\text {sample }}}{N}
$$

Figure $9 \mathrm{~b}$ presents the equivalent plastic strain sampled along the middle design path of the sawtooth. There are apparent differences in the C.S.I., shear band spacing $L_{S}$, and frequency of the serrated chips $f_{\text {chip }}$ under different parameters. Among them, the equivalent plastic strain value and distance $L_{s}$ of the hardening module $B$ are uniform, thereby indicating that the material constitutive parameter $B$ exhibits a small effect on the frequency and C.S.I. of the sawtooth chip. Other constitutive parameters $(A, C, n, m)$ affect the evident change in the equivalent plastic strain spacing $L_{S}$ and C.S.I.

Figure 10a presents the C.S.I. variation parameters under different constitutive parameters. The C.S.I. increases when the constitutive parameters $(A, C)$ increase. Conversely, C.S.I. decreases when the constitutive parameters $(B, n, m)$ increase. Among them, the hardening modulus $B$ exhibits the smallest effect on C.S.I., and the initial yield stress $A$ exhibits the largest effect. When the initial yield stress $A$ increases from $-30 \%$ to $+30 \%$ of the original parameter, C.S.I. increases from 1.2 to 14 , which is a 10.6 -fold increase. Owing to increasing in the initial yield stress $A$ increase the amount of heat generated, 
and equivalent plastic stress increases after compression in the shear zone after thermal softening.

(a)

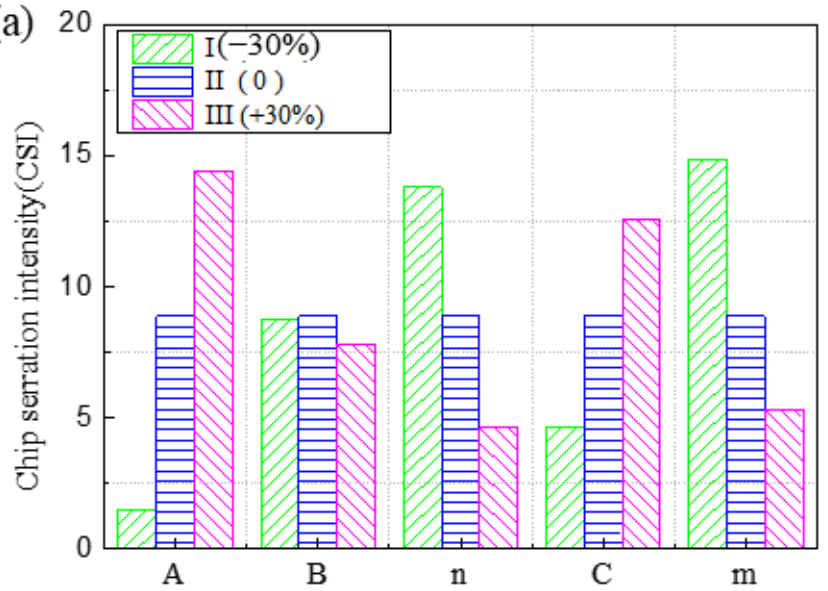

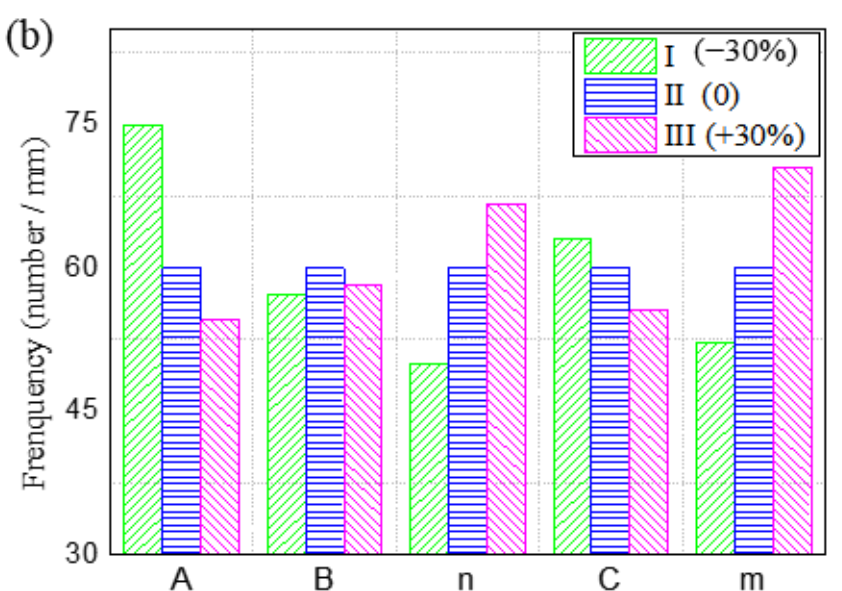

Figure 10. (a) Comparison of chip serration intensity (C.S.I.) under different J-C constitutive parameters $(A, B, n, C, m)$; (b) comparison of the frequency of serrated chip under different J-C constitutive parameters $(A, B, n, C, m)$; I, II, and III correspond to variations of the original $\mathrm{J}-\mathrm{C}$ constitutive parameters $(-30 \%, 0$, and $+30 \%$, respectively).

Figure $10 \mathrm{~b}$ indicates that the frequency of the serrated chip increases as the constitutive parameter $(A, C)$ increases; conversely, it decreases when the constitutive parameters $(B, n$, $m$ ) of the material increase. The frequency of the serrated chips is inversely proportional to the C.S.I. The results indicate that the decreases in the serrated frequency result in increased C.S.I. Although the number of serrations per unit length decreases, the damage to a single serration increases damage to the tool. Therefore, it is recommended to decrease the C.S.I. to a certain serrated frequency, which is conducive to reducing tool wear.

The dependence of the J-C parameter on the shear field temperature and cutting force is analyzed to further examine the effect of the constitutive parameters of Ti6Al4V on the formation mechanism of the serrated chip. Figure 11 presents the temperature field in the primary shear zone under different constitutive parameters. The temperature of the primary shear zone gradually increases when the initial yield stress $A$, the hardening modulus $B$, the strain rate dependency coefficient $C$, and the thermal softening coefficient $m$ increase from -30 to $+30 \%$ based on the original value. This is mainly due to the constitutive parameter $(A, B, C$, and $m)$ affecting the strength of the bond inside the material and increasing the energy required for the micro-cutting process, thereby increasing the amount of heat in the cutting zone.

Conversely, an increase in the hardening parameter $n$ decreases the temperature in the adiabatic shear zone. The serrated chips become less apparent with a decrease in temperature. This further proves that an increase in the hardening index decreases the serrated sensitivity coefficient.

Figure 12a presents the temperature of the chip sampled along the middle of the serrated chip. As shown in Figure 12a, the highest temperature in the second shear zone is due to friction between the tool and chips; thus, a significant amount of heat is generated on the rake face. The temperature of the adiabatic shear band (A.S.B.) exceeds the temperature on both sides of the adiabatic shear zone, which is mainly due to the plastic deformation in the adiabatic shear zone and low thermal conductivity of Ti6Al4V. Hence, heat in the shear zone is not transferred. 


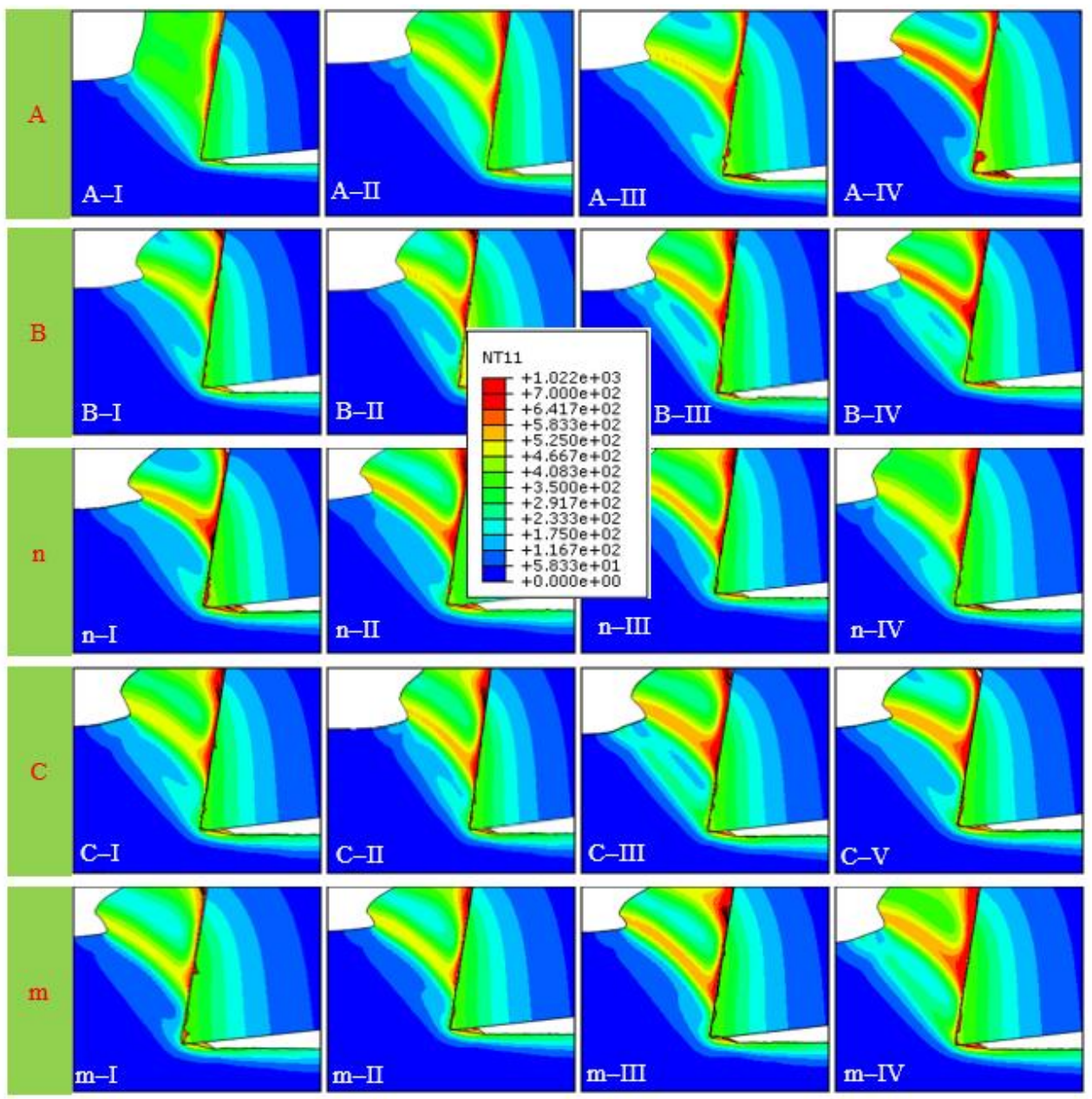

Figure 11. Temperature field under different $\mathrm{J}-\mathrm{C}$ parameters for cutting speed of $3 \mathrm{~m} / \mathrm{s}$. $A$ : initial yield stress, $B$ : hardening modulus, $n$ : strain rate dependency coefficient, $C$ : strain rate sensitivity coefficient, $m$ : thermal softening coefficient; I, II, III, and IV correspond to variation of the original J-C constitutive parameters $(-30 \%,-10 \%,+10 \%$, and $+30 \%$, respectively).
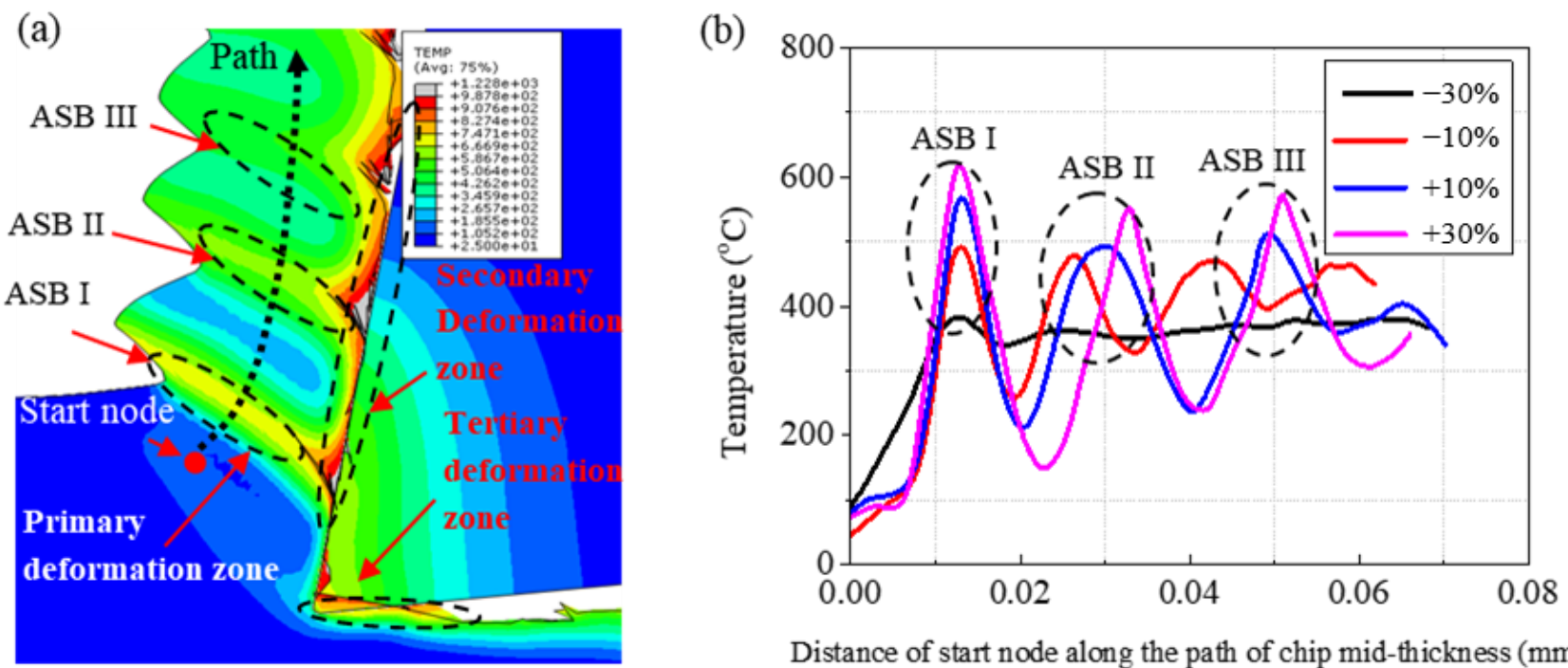

Distance of start node along the path of chip mid-thickness ( $\mathrm{mm}$ )

Figure 12. Temperature field during chip formation. (a) the design path along the middle thickness of the chip; (b) comparison of the temperature under different variations of the initial yield stress $A(-30 \%,-10 \%,+10 \%,+30 \%$, respectively). 
As shown in Figure 12b, the temperature of ASB I is the highest, and that of ASB III is the lowest. However, the temperature on both sides of ASB I is the lowest, and the temperature on both sides of ASB III is the highest. When the chips are discharged, the temperature of the adiabatic shear zone gradually passes to both sides, and the temperature difference between the adiabatic shear zone and its sides gradually decreases.

Figure 13 presents the changes in strain energy during the micro-cutting process of Ti6Al4V, where $a-i$ in Figure 13b corresponds to the strain energy of $a-i$ in Figure 13a, and $a^{\prime}-i^{\prime}$ in Figure 13b corresponds to the strain energy of $a^{\prime}-i^{\prime}$ in Figure 13a. The crests and troughs of each sawtooth are observed primarily because a significant amount of heat is generated via plastic deformation in the primary deformation zone during the formation of the serrated chip to form an adiabatic shear zone.
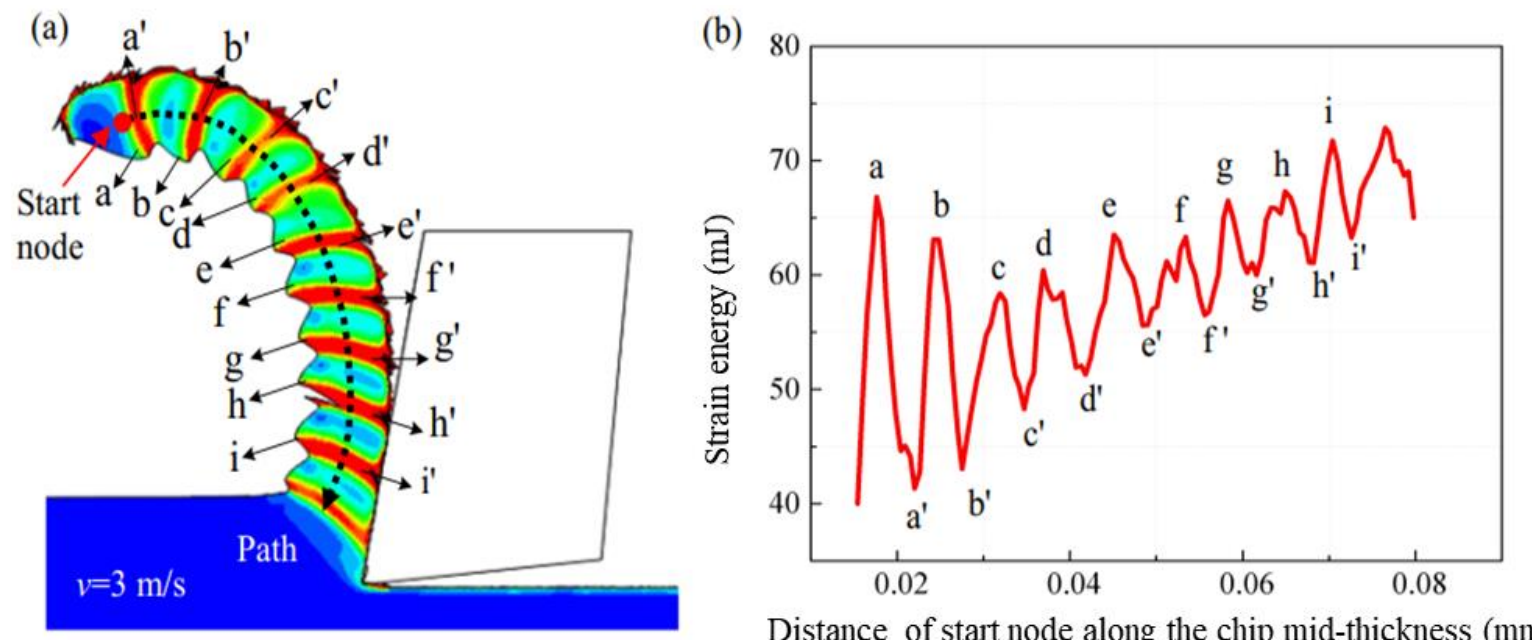

Distance of start node along the chip mid-thickness ( $\mathrm{mm}$ )

Figure 13. The strain energy during chip formation. (a) the design path along the middle of the chip; (b) variation of strain energy on serrated chips. $a-i$ point to the top of serrated chip, $a^{\prime}-i^{\prime}$ point to the root of serrated chip.

Figure 14a presents the curve of the cutting force during the micro-cutting process of Ti6Al4V. When the first serrated chip starts to form, the cutting force value is relatively high and then gradually decreases. The cutting force decreases to a minimum after the first serrated chip is formed. The subsequent serrated chip then repeats the aforementioned law of cutting force; this phenomenon can be confirmed in a previous study by Wang et al. [67]. The decrease in cutting force is due to the significant heat that is generated by the adiabatic shear zone, which makes the material softer and decreases the cutting force required for the cutting process, thereby resulting in periodic changes in the cutting force. This is because the cutting force changes periodically, and the tool generates a periodic vibration, thereby accelerating tool wear.

Figure $14 \mathrm{~b}$ presents the average cutting force under different J-C constitutive parameters. As shown in the figure, the cutting force corresponding to the initial yield tress $A$, the hardening modulus $B$, strain rate sensitivity coefficient $C$, and thermal softening coefficient $m$ gradually increase when the J-C material constitutive parameter increases from $-30 \%$ of the original value to $+30 \%$. Conversely, the cutting force parameter of the material hardening parameter $n$ decreases. The cutting force trend is consistent with the cutting heat in the shear zone, which indicates that an increase in the cutting force increases the amount of heat released. However, this does not indicate that increases in the amount of heat released promotes sawtooth sensitivity. 

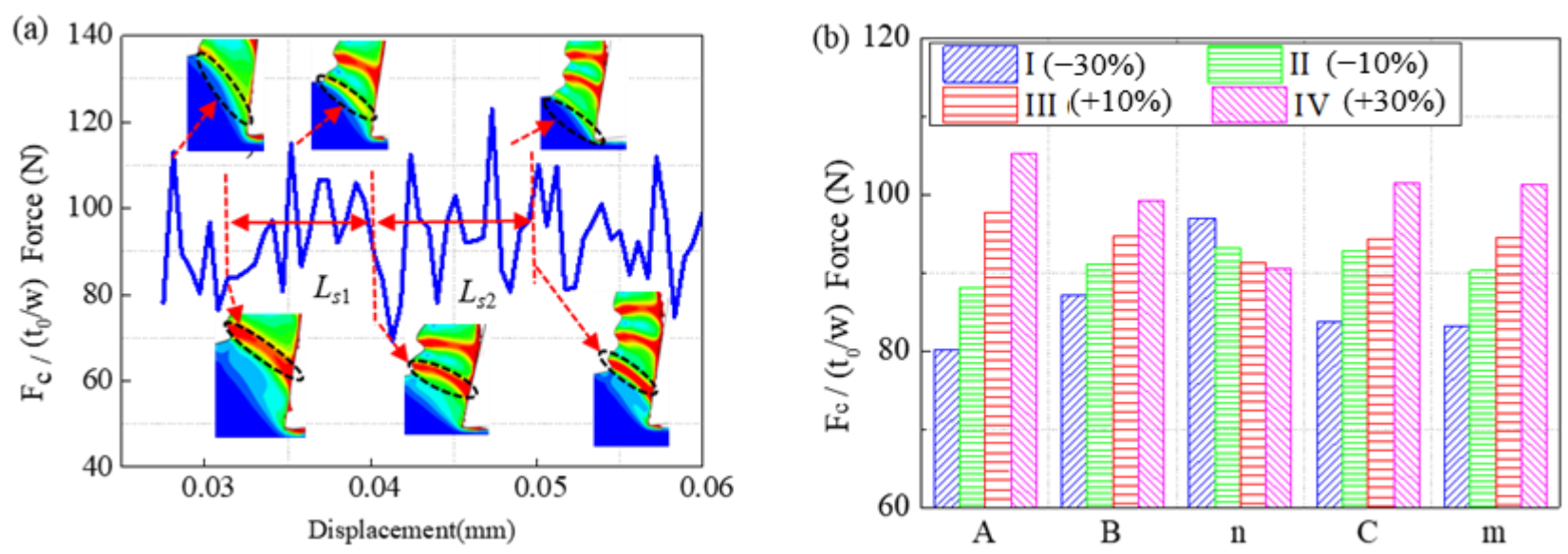

Figure 14. Analysis of average cutting force on serrated chips for cutting speed of $3 \mathrm{~m} / \mathrm{s}$. (a) Variation of cutting force in the formation of serrated chips; (b) comparison of average cutting force under different J-C constitutive parameters (A, B, n, C, m), I, II, III, and IV correspond to variation of the original J-C constitutive parameters $(-30 \%,-10 \%,+10 \%$, and $+30 \%$, respectively).

\subsection{Analysis of J-C Damage Parameters on the Formation of Serrated Chip}

The J-C damage parameter is an important factor governing material deformation and failure. To perform a detailed examination of the mechanism of the J-C damage parameters on the formation of serrated chips during the cutting simulation of Ti6Al4V, the Johnson-Cook damage parameter $\left(D_{1}, D_{2}, D_{3}, D_{4}\right.$, and $\left.D_{5}\right)$ is increased by $+50 \%,+100 \%$, and decreased by $50 \%$ and $100 \%$ based on the original parameters. The original J-C damage parameters are listed in Table 4.

Figure 15 presents the micro-cutting simulation results of the Ti6Al4V under different $\mathrm{J}-\mathrm{C}$ damage parameters; the J-C damage parameters apparently affect the serrated chip morphology under different gradient damage models. Specifically, when the $D_{2}$ damage parameter increases from $-100 \%$ to $100 \%$ of the original parameter, the serrated chip morphology of Ti6Al4V changes from the sawtooth to band morphology. Figure 16 indicates that the exponent factor $D_{2}$ mostly affects the sensitivity of the serrated chip morphology. The serrated chip increases with increases in the $D_{2}$ parameter; the sensitivity coefficient increases from $-80 \%$ to $+20 \%$.

Given that $D_{2}$ is the factor that maximally affects the sensitivity of the serrated chips, the equivalent plastic strain is sampled along the middle of the serrated chip morphology. As shown in Figure 17, the equivalent plastic strain strength decreases with increases in $D_{2}$. The chip serration intensity C.S.I. corresponds to 1.1 when $D_{2}$ increases to $100 \%$ of the initial value; the chip serration intensity C.S.I. corresponds to 8 when the material damage parameter $D_{2}$ decreases to the original parameter above $50 \%$. The results also indicate that the frequency of the serrated chip segmentation changes significantly. When the material damage parameter $D_{2}$ decreases, the peak value of the equivalent plastic strain adjacent to each other gradually increases, and the number of segments decreases. When the material damage parameter $D_{2}$ corresponds to $-100 \%$ of the original parameter, the Ti6Al4V serrated chip division frequency corresponds to $60 \mathrm{unit} / \mathrm{mm}$; the Ti6Al4V serrated chip division frequency corresponds to $35 \mathrm{unit} / \mathrm{mm}$ when the material damage parameter $D_{2}$ decreases to $100 \%$ of the original parameter. Therefore, the material damage parameters cannot be ignored for high-precision micro-cutting simulation models. 


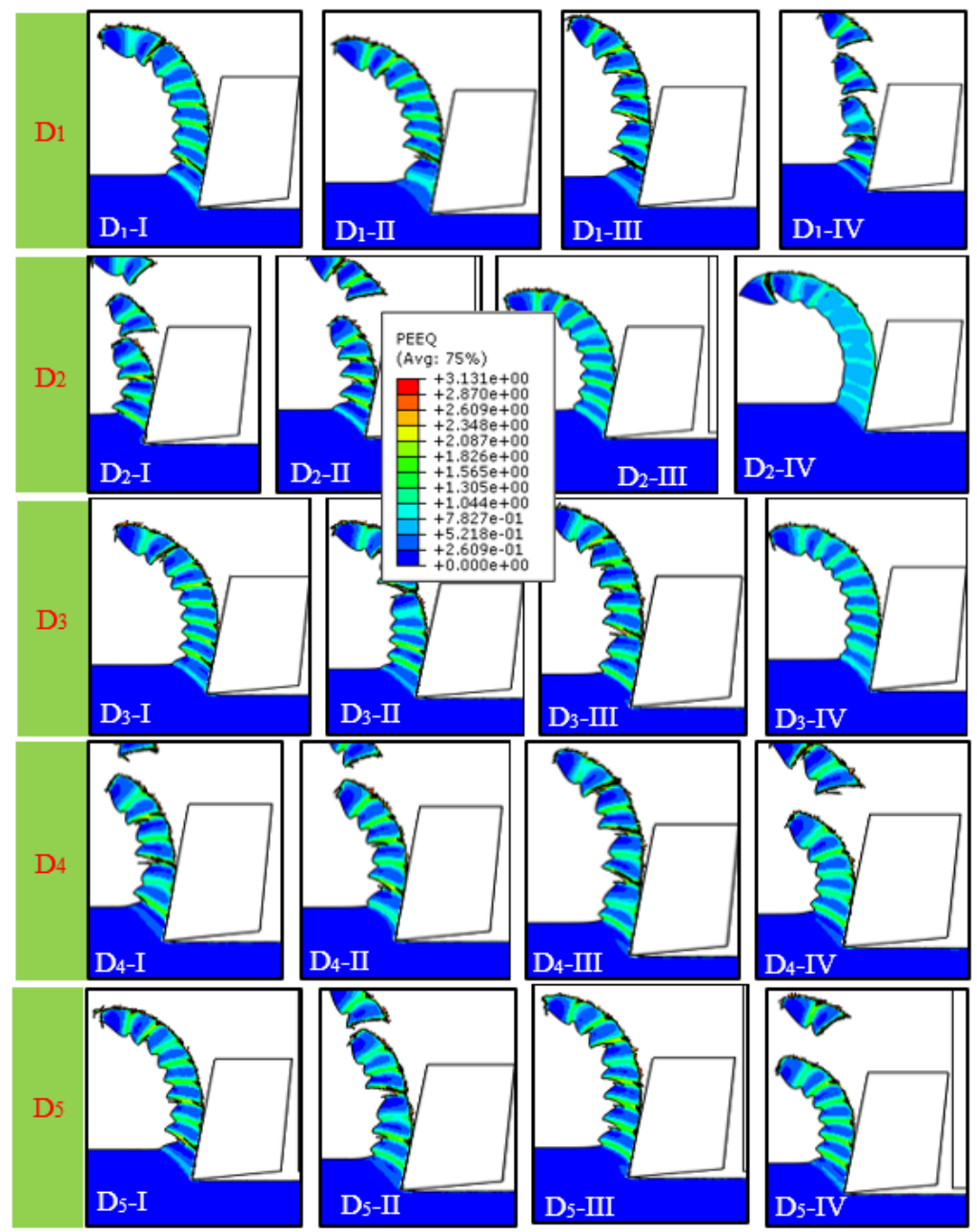

Figure 15. Serrated chip formation under different J-C damage parameters for a cutting speed of $3 \mathrm{~m} / \mathrm{s}$. $A$ : initial yield stress, $B$ : hardening modulus, $n$ : strain rate dependency coefficient, $C$ : strain rate sensitivity coefficient, $m$ : thermal softening coefficient; I, II, III, and IV correspond to variation of the original J-C damage parameters $(-100 \%,-50 \%,+50 \%$, and $+100 \%$, respectively).

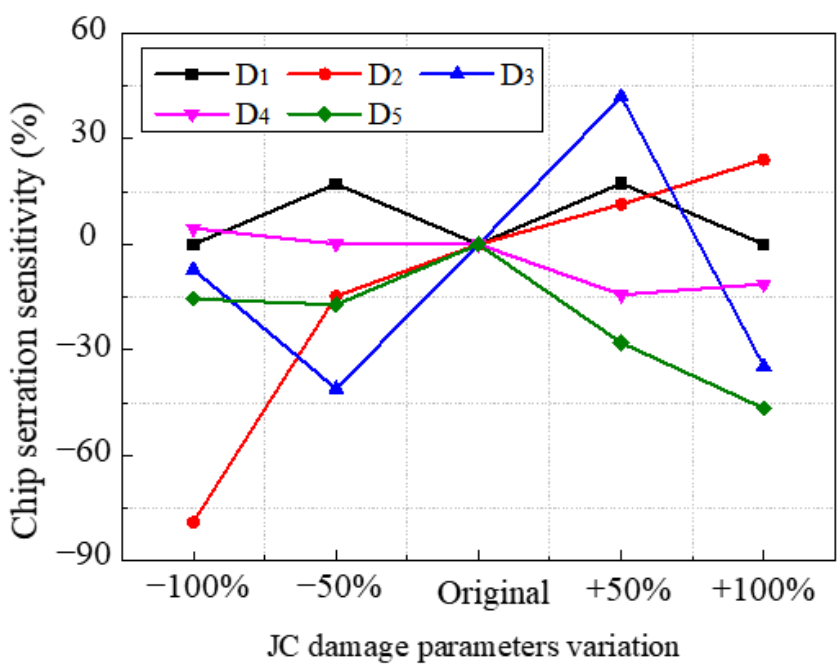

Figure 16. Sensitivity analysis of the serrated chip under different variations of the original J-C damage parameters. 


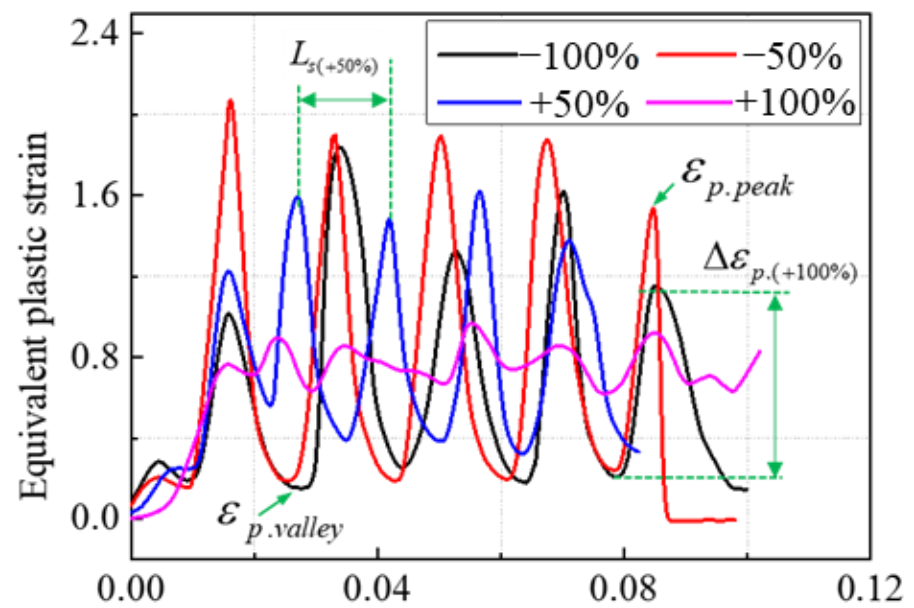

Distance of start node along the path of chip mid-thickness ( $\mathrm{mm})$

Figure 17. Comparison of the equivalent plastic strain under different variation of the exponent factor $D_{2}(-100 \%,-50 \%,+50 \%,+100 \%$, respectively).

Figure 18 presents the temperature value sampled along the middle of the Ti6Al4V serrated chip under different J-C damage parameters. As shown in the figure, the temperatures of the adiabatic shear band I, II, and III exceed the temperatures on both sides. The temperature from the adiabatic shear band I to III gradually decreases because the chips are no longer deformed by compression. When the material damage parameter $D_{2}$ increases from the original parameter to $+100 \%$, the temperature region of the serrated chip is stable, and evident wave peaks or valleys are not observed.

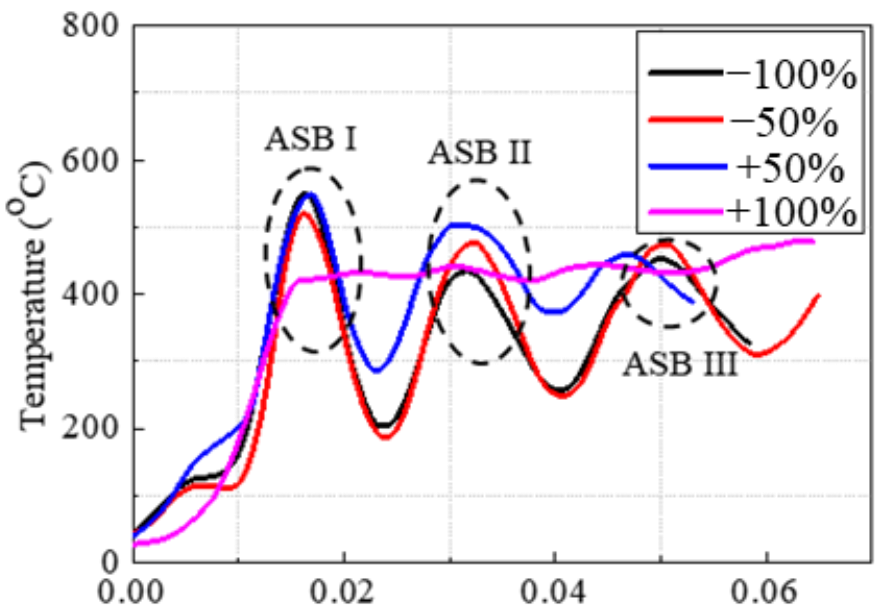

Distance of start node al ong the chip mid-thickness ( $\mathrm{mm}$ )

Figure 18. Comparison of the temperature under different variation of the exponent factor $D_{2}$ $(-100 \%,-50 \%,+50 \%,+100 \%$, respectively).

Figure 19 presents the corresponding cutting force under different J-C damage parameters. As shown in the figure, the damage parameter exhibits a low effect on the cutting force, and the cutting force changes within $10 \mathrm{~N}$. Specifically, when the cutting force of the exponent factor $D_{2}$ increases from $-100 \%$ to $+100 \%$, the cutting force increases by $6.7 \%$, and this is within the controllable range. Therefore, the J-C damage parameter exhibits a low effect on the cutting force of the sawtooth although the serrated chip and the temperature of the shear zone can significantly change. 


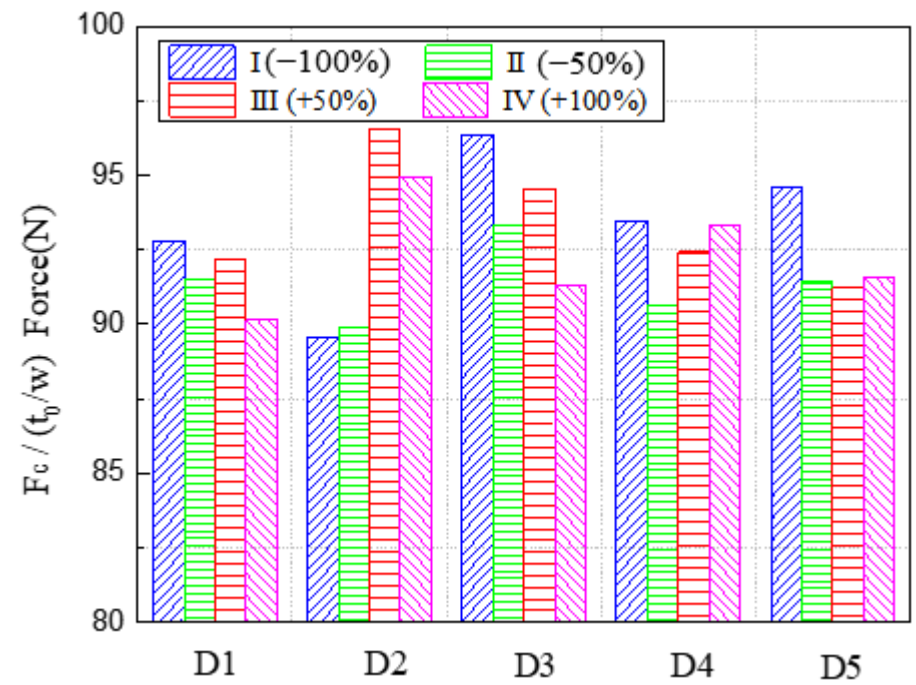

Figure 19. Comparison of average cutting force under different $\mathrm{J}$-C damage parameters $\left(D_{1}, D_{2}, D_{3}\right.$, $D_{4}$, and $\left.D_{5}\right)$. I, II, III, and IV correspond to variation of the original J-C damage parameters $(-100 \%$, $-50 \%,+50 \%$, and $+100 \%$, respectively).

\section{Conclusions}

This study mainly analyzed the dependence of J-C parameters on the formation mechanism of serrated chips. The J-C parameters of Ti6Al4V reported in previous studies differ significantly, which decreases the reliability of the cutting simulation. It also guides to improve the accuracy of cutting simulation models, as well as a reference for the selection of J-C constitutive parameters of simulation with Ti6Al4V manufactured with different heat treatments and additive manufacturing. The following conclusions were drawn:

1. Based on Abaqus/Explicit, a Ti6A14V micro-cutting simulation model was established, the formation process of Ti6Al4V serrated chips was analyzed in detail, and the law of stress $\mathrm{S}_{12}$ and the temperature field during the formation of Ti6Al4V serrated chip was revealed.

2. Among material constitutive parameters (i.e., $A, B, C, m$, and $n$ ), initial yield stress $A$ and thermal softening coefficient $m$ exhibited the greatest effect on the sensitivity coefficient of the sawtooth. Serrated segmentation frequency and C.S.I. depend on material constitutive parameters (i.e., $A, C$, $n$, and $m$ ), while the hardening modulus $B$ can be ignored.

3. The temperature field and cutting force were positively related to the material constitutive parameters (i.e., $A, B, C$, and $m$ ), and increase with increases in the constitutive parameters while the constitutive parameter $n$ decreases. Simultaneously, it was concluded that the temperature of the first adiabatic shear zone was the highest.

4. The cutting force value during the micro-cutting process periodically fluctuated with the formation of the sawtooth.

5. The damage parameters affected serrated chip sensitivity, serrated segmentation frequency, C.S.I., temperature field in the shear zone, and shear band spacing. However, the exponent factor $D_{2}$ exhibited the greatest effect.

Author Contributions: Conceptualization, Z.Z. and C.N.; methodology, Z.Z. and C.N.; software, Y.Y.; validation, Y.Y.; formal analysis, Z.Z.; investigation, Z.Z.; resources, Z.Z.; data curation, Z.Z.; writing-original draft preparation, Z.Z.; writing-review and editing, Y.B.; visualization, Z.Z.; supervision, X.J.; project administration, X.J.; funding acquisition, X.J. All authors have read and agreed to the published version of the manuscript.

Funding: This research was funded by National Pre-research Project, grant number 41423020201.

Institutional Review Board Statement: Not applicable. 
Informed Consent Statement: Not applicable.

Data Availability Statement: Data is contained within the article.

Acknowledgments: The authors would also like to thank Hao Wang (AML, NUS) for his assistance with cutting simulation.

Conflicts of Interest: The authors declare no conflict of interest.

\section{References}

1. Kumar, S.P.L.; Jerald, J.; Kumanan, S.; Prabakaran, R. A review on current research aspects in tool-based micromachining processes. Mater. Manuf. Process. 2014, 29, 1291-1337. [CrossRef]

2. Huo, D.; Cheng, K. Micro-Cutting: Fundamentals and Applications; John Wiley \& Sons, Ltd.: Hoboken, NJ, USA, 2013.

3. Zhao, Z.; To, S.; Zhu, Z.; Yin, T. A theoretical and experimental investigation of cutting forces and spring back behaviour of Ti6Al4V alloy in ultraprecision machining of microgrooves. Int. J. Mech. Sci. 2020, 169, 105315. [CrossRef]

4. Jackson, M.J.; Novakov, T.; Da Silva, M.B.; Machado, A.R. Predicting chip and non-chip formation when micromachining Ti-6Al-4V titanium alloy. Int. J. Adv. Manuf. Technol. 2016, 91, 955-985. [CrossRef]

5. Ducobu, F.; Rivière-Lorphèvre, E.; Filippi, E. Material constitutive model and chip separation criterion influence on the mod-eling of Ti6Al4V machining with experimental validation in strictly orthogonal cutting condition. Int. J. Mech. Sci. 2016, 107, 136-149. [CrossRef]

6. Zhao, Z.; To, S.; Zhuang, Z. Serrated chips formation in micro orthogonal cutting of Ti6Al4V alloys with equiaxial and martensitic microstructures. Micromachines 2019, 10, 197. [CrossRef] [PubMed]

7. Su, G.; Liu, Z.; Li, L.; Wang, B. Influences of chip serration on micro-topography of machined surface in high-speed cutting. Int. J. Mach. Tools Manuf. 2015, 89, 202-207. [CrossRef]

8. Ye, G.G.; Chen, Y.; Xue, S.; Dai, L. Critical cutting speed for onset of serrated chip flow in high speed machining. Int. J. Mach. Tools Manuf. 2014, 86, 18-33. [CrossRef]

9. Niu, W.; Mo, R.; Sun, H.; Gnanasekaran, B.; Zhu, Y.; Liu, G. A smooth particle hydrodynamic model for two-dimensional numerical simulation of Ti-6Al-4V serrated chip deformation based on TANH constitutive law. Proc. Inst. Mech. Eng. Part C J. Mech. Eng. Sci. 2018, 233, 3004-3017. [CrossRef]

10. Wang, H.; Kumar, A.S.; Riemer, O. On the theoretical foundation for the microcutting of calcium fluoride single crystals at elevated temperatures. Proc. Inst. Mech. Eng. Part B J. Eng. Manuf. 2016, 232, 1123-1129. [CrossRef]

11. Wang, H.; Riemer, O.; Brinksmeier, E. Theoretical study on the critical chip thickness in microcutting CaF2 single crystals with crystal plasticity finite element method. In Proceedings of the Euspen's 15th International Conference \& Exhibition, Leuven, Belgium, 1-5 June 2015; pp. 337-338.

12. Dandekar, C.R.; Shin, Y.C. Modeling of machining of composite materials: A review. Int. J. Mach. Tools Manuf. 2012, 57, 102-121. [CrossRef]

13. Ducobu, F.; Rivière-Lorphèvre, E.; Filippi, E. On the importance of the choice of the parameters of the Johnson-Cook constitutive model and their influence on the results of a Ti6Al4V orthogonal cutting model. Int. J. Mech. Sci. 2017, 122, 143-155. [CrossRef]

14. Mishra, S.K.; Ghosh, S.; Aravindan, S. Performance of laser processed carbide tools for machining of Ti6Al4V alloys: A combined study on experimental and finite element analysis. Precis. Eng. 2019, 56, 370-385. [CrossRef]

15. Calamaz, M.; Coupard, D.; Girot, F. A new material model for 2D numerical simulation of serrated chip formation when machining titanium alloy Ti-6Al-4V. Int. J. Mach. Tools Manuf. 2008, 48, 275-288. [CrossRef]

16. Zhu, Z.; To, S.; Zhu, W.-L.; Huang, P.; Zhou, X. Cutting forces in fast-/slow tool servo diamond turning of micro-structured surfaces. Int. J. Mach. Tools Manuf. 2019, 136, 62-75. [CrossRef]

17. Chaudhari, A.; Soh, Z.Y.; Wang, H.; Kumar, A.S. Rehbinder effect in ultraprecision machining of ductile materials. Int. J. Mach. Tools Manuf. 2018, 133, 47-60. [CrossRef]

18. Ducobu, F.; Rivière-Lorphèvre, E.; Filippi, E. Application of the Coupled Eulerian-Lagrangian (CEL) method to the modeling of orthogonal cutting. Eur. J. Mech. A/Solids 2016, 59, 58-66. [CrossRef]

19. Lee, Y.J.; Shen, Y.-K.; Wang, H. Suppression of polycrystalline diamond tool wear with mechanochemical effects in micromachining of ferrous metal. J. Manuf. Mater. Process. 2020, 4, 81. [CrossRef]

20. Gu, X.; Wang, H.; Liu, K. Modelling for material removal modes of monocrystalline sapphire by single-grit scratch. In Proceedings of the 21st International Symposium on Advances in Abrasive Technology (ISAAT), Toronto, ON, Canada, 14-18 October 2018.

21. Guo, J.; Zhang, J.; Wang, H.; Liu, K.; Kumar, A.S. Surface quality characterisation of diamond cut V-groove structures made of rapidly solidified aluminium RSA-905. Precis. Eng. 2018, 53, 120-133. [CrossRef]

22. Zang, J.; Zhao, J.; Li, A.; Pang, J. Serrated chip formation mechanism analysis for machining of titanium alloy Ti-6Al-4V based on thermal property. Int. J. Adv. Manuf. Technol. 2017, 98, 119-127. [CrossRef]

23. Xie, Q.; Zhu, Z.; Kang, G.; Yu, C. Crystal plasticity-based impact dynamic constitutive model of magnesium alloy. Int. J. Mech. Sci. 2016, 119, 107-113. [CrossRef]

24. Wang, L.; Qiao, J.; Wang, Z.; Jiao, Z.; Zhang, T.; Chen, G.; Zhao, D.; Zhang, Y.; Wang, Z.-H. Mechanical response and deformation behavior of $\mathrm{Al}_{0.6} \mathrm{CoCrFeNi}$ high-entropy alloys upon dynamic loading. Mater. Sci. Eng. A 2018, 727, 208-213. [CrossRef] 
25. Özel, T.; Karpat, Y. Identification of constitutive material model parameters for high-strain rate metal cutting conditions using evolutionary computational algorithms. Mater. Manuf. Process. 2007, 22, 659-667. [CrossRef]

26. Zhao, Y.; Sun, J.; Li, J.; Yan, Y.; Wang, P. A comparative study on Johnson-Cook and modified Johnson-Cook constitutive material model to predict the dynamic behavior laser additive manufacturing FeCr alloy. J. Alloys Compd. 2017, 723, 179-187. [CrossRef]

27. Zhou, T.; Wu, J.; Liang, Z.; Che, J.; Zhang, Y.; Wang, X. A novel constitutive model for Ti-6Al-4V alloy based on dislocation pile-up theory. Mater. Sci. Technol. 2017, 33, 1379-1387. [CrossRef]

28. Lee, W.-S.; Lin, C.-F. Plastic deformation and fracture behaviour of Ti-6Al-4V alloy loaded with high strain rate under various temperatures. Mater. Sci. Eng. A 1998, 241, 48-59. [CrossRef]

29. Leseur, D. Experimental Investigations of Material Models for Ti-6A1-4V and 2024-T3 Aluminum; DOT/FAA/AR-00/25; DTFA0397Z-90007; Office of Aviation Research: Washington, DC, USA, 2000.

30. Johnson, G.R. Strength and Fracture Characteristics of a Titanium Alloy (.06al, .04v) Subjected to Various Strains, Strain Rates, Temperatures and Pressures; NSWC TR 86-144: Dahlgren, VA, USA, 1985.

31. Sekar, K.S.V.; Kumar, M.P. Finite element simulations of Ti6Al4V titanium alloy machining to assess material model parameters of the Johnson-Cook constitutive equation. J. Braz. Soc. Mech. Sci. Eng. 2011, 33, 203-211. [CrossRef]

32. Gao, C.-Y.; Zhang, J.; Liu, P.-H. The role of material model in the finite element simulation of high-speed machining of Ti6Al4V. Proc. Inst. Mech. Eng. Part C J. Mech. Eng. Sci. 2016, 230, 2959-2967. [CrossRef]

33. Lee, W.-S.; Lin, C.-F. High-temperature deformation behaviour of Ti6Al4V alloy evaluated by high strain-rate compression tests. J. Mater. Process. Technol. 1998, 75, 127-136. [CrossRef]

34. Seo, S.; Min, O.; Yang, H. Constitutive equation for Ti-6Al-4V at high temperatures measured using the SHPB technique. Int. J. Impact Eng. 2005, 31, 735-754. [CrossRef]

35. Khan, H.; Suh, Y.S.; Kazmi, R. Quasi-static and dynamic loading responses and constitutive modeling of titanium alloys. Int. J. Plast. 2004, 20, 2233-2248. [CrossRef]

36. Braham Bouchnak, T. Etude du Comportement en Sollicitations Extrêmes et de l'Usinabilité d'un Nouvel Alliage de Titane Aéro-Nautique: Le ti555-3. Mécanique des Matériaux [physics.class-ph]; Arts et Métiers ParisTech-Centre de Angers: Paris, France, 2010.

37. Meyer, H.W., Jr.; Kleponis, D.S. Modeling the high strain rate behavior of titanium undergoing ballistic impact and penetration. Int. J. Impact Eng. 2001, 26, 509-521. [CrossRef]

38. Dorogoy, A.; Rittel, D. Determination of the Johnson-Cook material parameters using the SCS specimen. Exp. Mech. 2008, 49, 881-885. [CrossRef]

39. Vyas, A.; Shaw, M.C. Mechanics of saw-tooth chip formation in metal cutting. J. Manuf. Sci. Eng. 1999, 121, 163-172. [CrossRef]

40. Dumitrescu, M.; Elbestawi, M.A.; El-Wardany, T.I. Mist coolant applications in high speed machining of advanced materials. In Proceedings of the Third International Conference on Metal Cutting and High Speed Machining, Metz, France, 27-29 June 2002; pp. 329-339.

41. Aydın, M.; Köklü, U. Analysis of flat-end milling forces considering chip formation process in high-speed cutting of Ti6Al4V titanium alloy. Simul. Model. Pract. Theory 2020, 100, 102039. [CrossRef]

42. Thepsonthi, T.; Özel, T. Simulation of serrated chip formation in micro-milling of titanium alloy Ti-6Al-4V using 2D elas-toviscoplastic finite element modeling. Prod. Eng. 2016, 10, 575-586. [CrossRef]

43. Sahoo, P.; Pratap, T.; Patra, K. A hybrid modelling approach towards prediction of cutting forces in micro end milling of Ti-6Al-4V titanium alloy. Int. J. Mech. Sci. 2019, 150, 495-509. [CrossRef]

44. Sun, Z.; Shuang, F.; Ma, W. Investigations of vibration cutting mechanisms of Ti6Al4V alloy. Int. J. Mech. Sci. 2018, 148, 510-530. [CrossRef]

45. Bai, W.; Sun, R.; Roy, A.; Silberschmidt, V.V. Improved analytical prediction of chip formation in orthogonal cutting of titanium alloy Ti6Al4V. Int. J. Mech. Sci. 2017, 133, 357-367. [CrossRef]

46. Yadav, A.K.; Kumar, M.; Bajpai, V.; Singh, N.K.; Singh, R.K. FE modeling of burr size in high-speed micro-milling of Ti6Al4V. Precis. Eng. 2017, 49, 287-292. [CrossRef]

47. Wan, M.; Wen, D.-Y.; Ma, Y.-C.; Zhang, W.-H. On material separation and cutting force prediction in micro milling through involving the effect of dead metal zone. Int. J. Mach. Tools Manuf. 2019, 146, 103452. [CrossRef]

48. Kim, D.Y.; Kim, D.M.; Park, H.W. Predictive cutting force model for a cryogenic machining process incorporating the phase transformation of Ti-6Al-4V. Int. J. Adv. Manuf. Technol. 2018, 96, 1293-1304. [CrossRef]

49. Du, M.; Cheng, Z.; Wang, S. Finite element modeling of friction at the tool-chip-workpiece interface in high speed machining of Ti6Al4V. Int. J. Mech. Sci. 2019, 163, 105100. [CrossRef]

50. Banerjee, N.; Sharma, A. Development of a friction model and its application in finite element analysis of minimum quantity lubrication machining of Ti-6Al-4V. J. Mater. Process. Technol. 2016, 238, 181-194. [CrossRef]

51. Ming, W.; Chen, J.; An, Q.; Chen, M. Dynamic mechanical properties and machinability characteristics of selective laser melted and forged Ti6Al4V. J. Mater. Process. Technol. 2019, 271, 284-292. [CrossRef]

52. Mandil, G.; Paris, H.; Le, V.T.; Suard, M. Building new entities from existing titanium part by electron beam melting: Microstructures and mechanical properties. Int. J. Adv. Manuf. Technol. 2016, 85, 1835-1846. [CrossRef]

53. Yaich, M.; Ayed, Y.; Bouaziz, Z.; Germain, G. Numerical analysis of constitutive coefficients effects on FE simulation of the 2D orthogonal cutting process: Application to the Ti6Al4V. Int. J. Adv. Manuf. Technol. 2017, 93, 283-303. [CrossRef] 
54. Wang, B.; Liu, Z. Shear localization sensitivity analysis for Johnson-Cook constitutive parameters on serrated chips in high speed machining of Ti6Al4V. Simul. Model. Pract. Theory 2015, 55, 63-76. [CrossRef]

55. Calamaz, M.; Coupard, D.; Nouari, M.; Girot, F. Numerical analysis of chip formation and shear localisation processes in machining the Ti-6Al-4V titanium alloy. Int. J. Adv. Manuf. Technol. 2011, 52, 887-895. [CrossRef]

56. Özel, T.; Yildiz, S.; Ciurana, J. Influence of material models on serrated chip formation in simulation of machining Ti-6Al-4V titanium alloy. In Proceedings of the 12th CIRP Conference on Modeling of Machining Operations, Donostia-San Sebastián, Spain, 7-8 May 2009; pp. 123-130.

57. Lee, W.; Wang, H.; Chan, C.; To, S. Finite element modelling of shear angle and cutting force variation induced by material anisotropy in ultra-precision diamond turning. Int. J. Mach. Tools Manuf. 2013, 75, 82-86. [CrossRef]

58. Özel, T.; Zeren, E. Finite element modeling the influence of edge roundness on the stress and temperature fields induced by high-speed machining. Int. J. Adv. Manuf. Technol. 2006, 35, 255-267. [CrossRef]

59. Ye, G.G.; Xue, S.F. Thermal gradient and its contribution to size effect of specific cutting energy. Int. J. Adv. Manuf. Technol. 2019, 101, 2327-2339. [CrossRef]

60. Ni, C.; Zhu, L. Investigation on machining characteristics of TC4 alloy by simultaneous application of ultrasonic vibration assisted milling (UVAM) and economical-environmental MQL technology. J. Mater. Process. Technol. 2020, 278, 116518. [CrossRef]

61. Mabrouki, T.; Rigal, J.-F. A contribution to a qualitative understanding of thermo-mechanical effects during chip formation in hard turning. J. Mater. Process. Technol. 2006, 176, 214-221. [CrossRef]

62. Xu, J.; El Mansori, M. Cutting modeling of hybrid CFRP/Ti composite with induced damage analysis. Materials 2016, 9, 22. [CrossRef] [PubMed]

63. Mabrouki, T.; Girardin, F.; Asad, M.; Rigal, J.-F. Numerical and experimental study of dry cutting for an aeronautic aluminium alloy (A2024-T351). Int. J. Mach. Tools Manuf. 2008, 48, 1187-1197. [CrossRef]

64. Johnson, G.R.; Cook, W.H. Fracture characteristics of three metals subjected to various strains, strain rates, temperatures and pressures. Eng. Fract. Mech. 1985, 21, 31-48. [CrossRef]

65. Chen, G.; Ren, C.; Yang, X.; Jin, X.; Guo, T. Finite element simulation of high-speed machining of titanium alloy (Ti-6Al-4V) based on ductile failure model. Int. J. Adv. Manuf. Technol. 2011, 56, 1027-1038. [CrossRef]

66. Zorev, N.N. Inter-relationship between shear processes occurring along tool face and shear plane in metal cutting. Int. Res. Prod. Eng. 1963, 49, 143-152.

67. Shet, C.; Deng, X. Residual stresses and strains in orthogonal metal cutting. Int. J. Mach. Tools Manuf. 2003, 43, 573-587. [CrossRef]

68. Wang, H.; To, S.; Chan, C.; Cheung, C.; Bin Lee, R. Elastic strain induced shear bands in the microcutting process. Int. J. Mach. Tools Manuf. 2010, 50, 9-18. [CrossRef]

69. Shaw, M.; Vyas, A. Chip formation in the machining of hardened steel. CIRP Ann. 1993, 42, 29-33. [CrossRef]

70. Komanduri, R.; Von Turkovich, B. New observations on the mechanism of chip formation when machining titanium alloys. Wear 1981, 69, 179-188. [CrossRef]

71. Dargusch, M.S.; Sun, S.; Kim, J.W.; Li, T.; Trimby, P.; Cairney, J.M. Effect of tool wear evolution on chip formation during dry machining of Ti-6Al-4V alloy. Int. J. Mach. Tools Manuf. 2018, 126, 13-17. [CrossRef]

72. Liu, C.R.; Guo, Y.B. Finite element analysis of the effect of sequential cuts and tool-chip friction on residual stresses in a ma-chined layer. Int. J. Mech. Sci. 2000, 42, 1069-1086. [CrossRef]

73. Schulz, H.; Abele, E.; Sahm, A. Material aspects of chip formation in HSC machining. CIRP Ann. 2001, 50, 45-48. [CrossRef] 